\title{
Vibration Analysis of Reinforced Concrete Simply Supported Beam versus Variation Temperature
}

\author{
Hanbing Liu, Hua Wang, Guojin Tan, Ziyu Liu, and Yongchun Cheng \\ College of Transportation, Jilin University, Changchun 130022, China \\ Correspondence should be addressed to Guojin Tan; tgj@jlu.edu.cn
}

Received 13 February 2017; Revised 24 May 2017; Accepted 3 July 2017; Published 3 August 2017

Academic Editor: Emiliano Mucchi

Copyright (c) 2017 Hanbing Liu et al. This is an open access article distributed under the Creative Commons Attribution License, which permits unrestricted use, distribution, and reproduction in any medium, provided the original work is properly cited.

\begin{abstract}
It is well known that temperature has great influence on modal characteristics of bridges. The relationship between them has been studied by using statistical mathematics, numerical analysis, and field's monitoring methods, which have relatively narrow applicability. Therefore, it is necessary to analyze their relationship theoretically. In this paper, the relationship between temperature and modal characteristics of the simply supported beam is investigated based on theoretical calculation method. Firstly, the temperature field is analyzed to find out the main factors that lead to the changes of modal characteristics. Secondly, the dynamic equations of simply supported beam under the effect of temperature are established. Next, a test beam is constructed to validate the proposed calculation method experimentally. The calculated results are in good agreement with those from the experiment. Finally, the proposed method is successfully applied to real engineering.
\end{abstract}

\section{Introduction}

It was proved practically that vibration-based structural damage detection technique is easy and convenient [1-3]. However, the measured modal characteristics inevitably contain the effect of environmental factors and have large error which may lead to wrong results [4-6]. Some studies have found that the changes in structure responses due to environmental variation could be more significant than the changes due to normal structural damage [7]. A thorough study of the variability induced by environmental factors in modal characteristics must be conducted before modal-based damage identification algorithms can be applied with any confidence $[3,8,9]$. A wealth of research results shows that the temperature is the most important environmental factor which affects the change of bridges' modal characteristics [10-15].

Over the past few decades, quite a few studies have been conducted to investigate the environmental effect on structural modal characteristics. Cornwell et al. [11] have tested the natural frequency of the Alamosa Canyon Bridge without traffic loads and found that the natural frequency of the first mode varied by approximately $5 \%$ over 24 -hour time period. He et al. [16] tested the Voigt Bridge to investigate corresponding natural frequency without traffic loads. It is shown that the changes of 1st natural frequencies induced by environmental temperature are $10 \%-20 \%$. The results from a continuous monitoring on the Dowling Hall Footbridge by Moser and Moaveni [17] also indicated that the first six order natural frequencies have a significant variability about $4 \%-8 \%$ correlated with temperature. The Z24-bridge in Switzerland was monitored during almost one year by Peeters et al. $[18,19]$. The natural frequency differences ranging from $14 \%$ to $18 \%$ had to be explained by normal environmental changes. Kim et al. [3] studied a $2 \mathrm{~m}$ span stainless steel, plate-girder bridge model. In all modes, natural frequencies decreased as the temperature increases and the obtained natural frequencies changed by $4 \%$ as the test temperature varied from $-3^{\circ} \mathrm{C}$ to $23^{\circ} \mathrm{C}$. Zabel et al. [20] investigated the dynamic behavior of a typical short span railway bridge for a long-term observation. The experimental results made obvious that the natural frequencies varied up to approximately $30 \%$ between summer and winter. A finite-element model updating with respect to measured parameters for the sensitivity analysis showed that the structural elastic modulus and the bearing shear modulus had the most influence on the natural frequencies.

Meanwhile, it has been observed that the changes of natural frequencies due to temperature variation can be more 
pronounced than those caused by medium structural damage [5] or vehicle loads [21]. For example, Kim et al. [1] carried out experiments on model plate-girder bridges under the effect of various temperatures. For undamaged bridges, the first four modes were measured when temperatures are $0-30^{\circ} \mathrm{C}$, and the 1st natural frequency varied from $76.150 \mathrm{~Hz}$ to $63.164 \mathrm{~Hz}$. For damaged ones, the natural frequency reduced from $66.196 \mathrm{~Hz}$ to $62.475 \mathrm{~Hz}$ as the stiffness of the cross section decreased by approximately 30\%. Alampalli [22] conducted several tests over 9 months on an abandoned steel-stringer bridge to examine the sensitivity of measured modal parameters with respect to variations resulting from test environmental conditions under intact and simulateddamage conditions and presented a conclusion that the sensitivity of temperature is larger than that of damage. Siddique et al. [23] used vibration-based damage detection methods (VBDD) to detect small-scale damage on a twospan, integral abutment overpass structure. The lowest three measured natural frequencies decreased by $7.8 \%$ to $12.0 \%$ as the ambient temperature increased from $-12^{\circ} \mathrm{C}$ to $40^{\circ} \mathrm{C}$. Corresponding changes due to damage were much lower, suggesting that natural frequencies are not a sufficiently sensitive indicator of small-scale damage. A series of damage tests were carried out by Peeters and De Roeck [24]. The results showed that the natural frequency changed by $10 \%$ until the structure was destroyed [25] and was less than the variation of $14 \%-18 \%$ induced by environmental factors.

In summary, it has been widely observed that temperature has a significant effect on modal characteristics of bridges [26]. The feasibility of vibration-based damage detection, however, is limited when their changes involve the effect of temperature, particularly for large structures [8].

In view of this, some studies try to analyze the natural frequency-temperature relationships; for example, $\mathrm{Ni}$ et al. [27] used the relative flexibility change (RFC) between intact and damage states as an index to locate damage of the cable-stayed Ting Kau Bridge. It is revealed that, in the absence of ambient effects, the RFC index performed well for locating damage of different severities in singledamage cases. However, eliminating ambient effects (temperature change and traffic load) is requisite for reliable detection of damage at stay cables and cross girders. Jin et al. [28] investigated an in-service highway bridge for longterm structural health monitoring. The bilinear relationship between natural frequency and temperature are analyzed using autocorrelation function and cross-correlation function; besides, damage detection method based on Artificial Neutral Network can estimate structural damage effectively. Based on the Autoregressive and Exogenous model, Peeters and De Roeck [24] proposed a methodology to distinguish these temperature effects from real damage events on the Z24 bridge. Ding and Li [29] investigated the daily and seasonal correlations of frequency-temperature using the output-only modal frequency identification obtained by the Iterative Windowed Curve-fitting Method (IWCM) for the Runyang Suspension Bridge. Zhou et al. [30] formulated a correlation model with the backpropagation neural network (BPNN) technique to eliminate the temperature effect. $\mathrm{Ni}$ et al. [31] investigated the cable-stayed Ting Kau Bridge and found that the relative variation of the measured temperatureinduced frequencies under weak wind conditions range from $3.22 \%$ to $15.07 \%$. However, the relative variation of the modal frequencies arising from wind effect is estimated to range from $1.61 \%$ to $7.87 \%$, being notably less than the modal variability caused by temperature effect. Breccolotti et al. [32] used FEM thermal analysis to numerically compute the dynamic response of the structure. Xia et al. [33] had carried out periodically vibration tested for a reinforced concrete slab for nearly two years. It is found that the frequencies have a strong negative correlation with temperature and damping ratios have a positive one. The test results obtained in this study indicated that the first two modal frequencies decrease by $0.23 \%$ when temperature increases by one degree. Based on the nonlinear dynamic finiteelement model of a two-span, slightly skewed continuous bridge, $\mathrm{Fu}$ and DeWolf [34] had accounted for changes in the vibrational behavior due to the eccentrically applied bearing forces, which occurred when the bearings were partially restrained in colder weather. Xu and Zhishen [6] established a 3D finite model of a cable-stayed bridge with box section and analyzed the effects of temperature on the frequencies. Mosavi et al. [35] investigated a two-span steel-concrete composite bridge in North Carolina, USA, and addressed the extent and reason of the daily changes observed in its dynamic properties. Numerical simulations of the bridge were used along with the recorded temperatures and deflections to suggest a possible reason for the observed changes in the natural frequencies of the bridge. Moreover, Xia et al. [36] investigated the variation of the structural modal characteristics versus the nonuniform temperature field of the structure. A good linear correlation between the natural frequencies measured and the structural temperatures other than the air temperature or surface temperatures is observed. Liu et al. [37] also pointed out nonuniform temperature distribution is necessary to be considered in correlation analysis between modal frequencies and temperature.

It should be noted that most of researches about the influence of temperature on modal characteristics of bridges are mainly concentrated on the real bridge test and analyzed the relationship between them by the mathematical statistics and other analytical methods. Besides, some scholars employed numerical simulation or laboratory test methods to analyze the influence of temperature on structural modal characteristics. However, more in-depth theoretical analysis is very rare, especially based on the beam vibration theory. Thus, to analyze and to clarify the internal mechanism of temperature influencing structural modal characteristics by the basic theory of vibration equations are needed.

The purpose of present study was to investigate the relationship between temperature and modal characteristics based on the vibration theory for the simply supported beam. Firstly, the temperature field distribution of the beam will be analyzed to find out the main factors (i.e., the elastic modulus, the deflection of beam, and boundary conditions) which lead to the changes of modal characteristics. Secondly, considering the above three factors, the dynamic equations of simply supported beam under the effect of temperature 


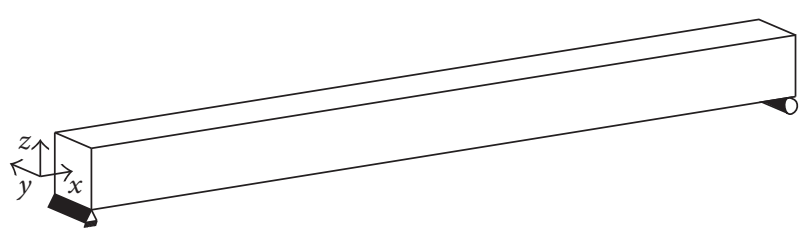

FIGURE 1: The simply supported beam model.

are established. Finally, the proposed calculation method is validated experimentally and applied to a real structure.

\section{Analysis of Temperature Field in Beam}

The $z$-axis vibration of simply supported beam was considered in this paper shown in Figure 1. Therefore, by adopting the $y$-axis average temperature, the temperature distribution along the $z$-axis could be obtained, as shown in Figure 2 . The temperature in Figure 2(a) can be decomposed into three parts, that is, uniform temperature (Figure 2(b)), linear temperature gradient (Figure 2(c)), and nonlinear temperature gradient (Figure 2(d)).

Free strain $\varepsilon_{t(z)}$ along the longitudinal direction ( $x$-axis) of beam under the effect of temperature is

$$
\varepsilon_{t(z)}=\alpha_{c} t(z),
$$

where $\alpha_{c}$ is the thermal expansion coefficient of concrete and $t(z)$ is the temperature at point $z$.

Assuming the beam obeys the plane section assumption, the final strain $\varepsilon_{f(z)}$ is linearly distributed, that is,

$$
\varepsilon_{f(z)}=\varepsilon_{0}+\psi z,
$$

where $\varepsilon_{0}$ is the strain at the neutral axis and $\psi$ is the angle, shown in Figure 3, and $z$ is the vertical coordinate.

Due to the longitudinal mutual constraint in beam, the nonlinear temperature gradient in Figure 2(d) will produce self-stress $\sigma_{s(z)}$ at point $z$ :

$$
\sigma_{s(z)}=E\left(\varepsilon_{t(z)}-\varepsilon_{f(z)}\right),
$$

where $E$ is the elastic modulus.

For simply supported beam, the bending moment $M$ and axial force $N$ caused by temperature are all zero, that is,

$$
\begin{aligned}
& M=\int_{A} \sigma_{s(z)} z d A=0 \\
& N=\int_{A} \sigma_{s(z)} d A=0,
\end{aligned}
$$

where $A$ is the cross-sectional area.

As can be seen from (4), structural internal forces are not produced by self-stress for simply supported beam, which may indicate that modal characteristics will not be affected by self-stress.
Substituting (1) and (2) into (3) and the resulting expression into (4) yields

$$
\begin{aligned}
N= & \int_{h} E \alpha_{c} t_{(z)} b d z-\varepsilon_{0} \int_{h} E b d z-\psi \int_{h} E b z d z=0 \\
M= & \int_{h} E \alpha_{c} t_{(z)} b\left(z-z_{c}\right) d z-\varepsilon_{0} \int_{h} E b\left(z-z_{c}\right) d z \\
& -\psi \int_{h} E b z\left(z-z_{c}\right) d z=0,
\end{aligned}
$$

where $b$ is the cross-sectional width, $h$ is the cross-sectional height, and $z_{c}$ is the neutral axis depth.

Then the parameters $\varepsilon_{0}$ and $\psi$ in Figure 3 could be calculated as follows:

$$
\left\{\begin{array}{l}
\varepsilon_{0} \\
\psi
\end{array}\right\}=\left[\begin{array}{ll}
N_{1} & N_{2} \\
N_{3} & N_{4}
\end{array}\right]^{-1}\left\{\begin{array}{l}
N_{5} \\
N_{6}
\end{array}\right\}
$$

where

$$
\begin{aligned}
& N_{1}=\int_{h} E b d z, \\
& N_{2}=\int_{h} E b z d z, \\
& N_{3}=\int_{h} E b\left(z-z_{c}\right) d z, \\
& N_{4}=\int_{h} E b z\left(z-z_{c}\right) d z, \\
& N_{5}=\int_{h} E \alpha_{c} t_{(z)} b d z, \\
& N_{6}=\int_{h} E \alpha_{c} t_{(z)} b\left(z-z_{c}\right) d z .
\end{aligned}
$$

Thus, we can obtain strains caused by three decomposed parts in Figure 2 according to (2), (3), and (6). Temperature of the first decomposed part will stretch or shorten the beam in the longitudinal direction, while, for the simply supported beam, there is no effect. The second part will cause the beam to be deflected and the third part will lead to self-stress shown in (3). Therefore, the influence of the last two parts on modal characteristics of the beam will be considered in the following theoretical analysis.

\section{Theoretical Analysis}

Based on the temperature field analysis in Figure 2 and Euler-Bernoulli beam theory, this paper will analyze the influence of temperature on modal characteristics of simply supported beam from the following aspects: (1) the influence of temperature on the elastic modulus [6]; (2) the influence of temperature on the deflection of beam [38]; (3) the influence of self-stress caused by temperature on modal characteristics.

3.1. The Influence of Self-Stress Caused by Temperature on Modal Characteristics of Beam. The relationship between self-stress $\sigma_{s}(z)$ and self-strain $\varepsilon_{\sigma(z)}$ could be expressed as 


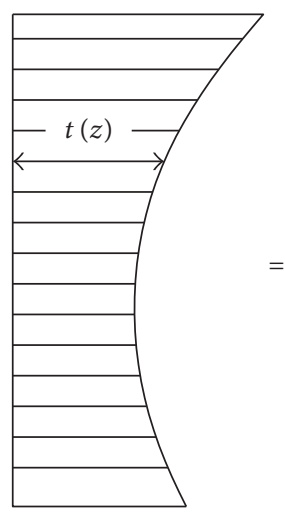

(a)

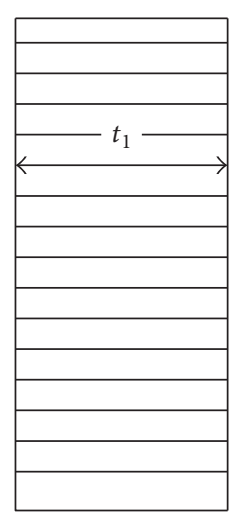

(b)

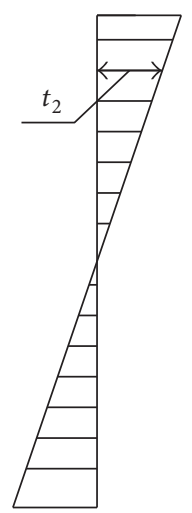

(c)

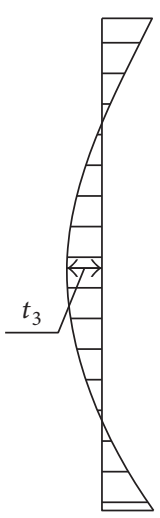

(d)

Figure 2: The diagram of temperature decomposition.

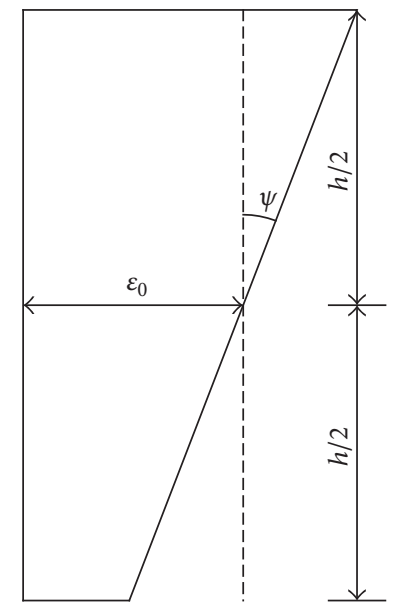

FIgURE 3: The final strain under the plane section assumption.

follows:

$$
\sigma_{s}(z)=E \varepsilon_{\sigma(z)} .
$$

Substituting (8) into (4) results in

$$
\begin{aligned}
\int_{A} E \varepsilon_{\sigma(z)} d A & =0 \\
\int_{A} E \varepsilon_{\sigma(z)} z d A & =0 .
\end{aligned}
$$

According to the Hamilton principle, there is

$$
\delta \int_{t_{1}}^{t_{2}}(T-V+W) d t=0,
$$

where $T, V$, and $W$ are the kinetic energy, the potential energy, and the work done by the self-stress, respectively.

Thus, the work $W$ done by the self-stress in (11) can be expressed as follows:

$$
W=\int_{V} \sigma_{s(z)} \varepsilon d V
$$

where $\varepsilon=z w^{\prime \prime}$ and $w$ is the vertical displacement.
Substituting (8) into (12), one obtains

$$
\begin{aligned}
W & =\int_{0}^{l} \int_{A} E \varepsilon_{\sigma(y)} z w^{\prime \prime} d A d x \\
& =\int_{0}^{l} w^{\prime \prime} \int_{A} E \varepsilon_{\sigma(z)} z d A d x .
\end{aligned}
$$

According to (10), $W=0$, which indicates that the self-stress caused by temperature has no influence on modal characteristics. It also verifies the conclusions drawn after (4).

3.2. Dynamic Equations of Simply Supported Beam under the Effect of Temperature. For the moment, the temperature distribution along the $x$-axis of the beam is assumed to be identical, which will become an arch under the effect of the linear temperature gradient in Figure 2(c). In addition, the shear stiffness of the bearing is taken into account. Therefore, the model of simply supported beam under the effect of temperature is adopted as shown in Figure 4. In which $k_{t 1}$ and $k_{t 2}$ are shear stiffness of the left and right bearing and $w, v$, and $u$ are the radial displacement, the tangential displacement, and the rotation due to the bending along the $\varphi$ coordinate, respectively. Furthermore, $R$ is the radius of curvature along the $\varphi$ coordinate and $\Phi$ is the curve angle.

The relationship between the elastic modulus and temperature is [36] as follows:

$$
E(x, y, z)=E_{20}\left\{1-\theta_{E}[T(x, y, z)-20]\right\},
$$

where $E_{20}$ is the elastic modulus of concrete at $20^{\circ} \mathrm{C}$ and $T(x, y, z)$ is the temperature in Cartesian coordinates. $\theta_{E}$ is the temperature coefficient of elastic modulus of concrete.

According to the experimental data reported by Baldwin and North [39], $\theta_{E}$ is

$$
\theta_{E}= \begin{cases}-4.5 \times 10^{-3} /{ }^{\circ} \mathrm{C}, & t<100^{\circ} \mathrm{C} \\ -1.4 \times 10^{-3} /{ }^{\circ} \mathrm{C}, & t>100^{\circ} \mathrm{C} .\end{cases}
$$

Our research group has studied the relationship between the elastic modulus and temperature [40] and obtained a 


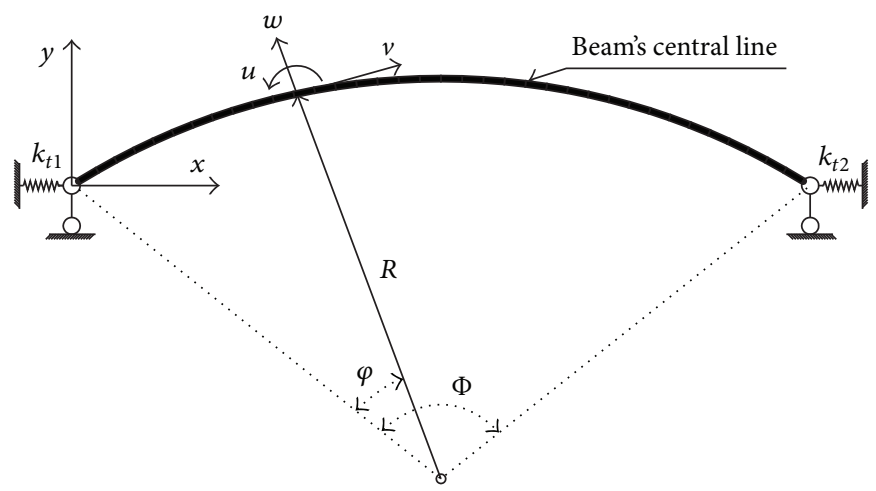

FIGURE 4: The model of the simply supported beam under the effect of temperature.

relationship for temperature between $-20^{\circ} \mathrm{C}$ and $60^{\circ} \mathrm{C}$ similar to (14), which verified the appropriateness of (14). However, due to the limited temperature range of our relationship, (14) is adopted for a wider range of temperature.

As the moment of inertia and shear deformation are ignored, the force analysis taking from any microsegment in Figure 4 is shown in Figure 5, in which $M, Q, N, P_{\varphi}$, and $P_{r}$ are the bending moment, the shear force, the axial force, the tangential inertia force, and the radial inertia force, respectively.

Based on D'Alembert's principle, the equilibrium equations are as follows:

$$
\begin{aligned}
\frac{\partial N}{\partial \varphi} & =-R P_{\varphi}-Q \\
\frac{\partial Q}{\partial \varphi} & =N-R P_{r} \\
\frac{\partial M}{\partial \varphi} & =R Q .
\end{aligned}
$$

Substituting (18) into (16) and (17) yields

$$
\begin{aligned}
\frac{\partial N}{\partial \varphi} & =-R P_{\varphi}-\frac{1}{R} \frac{\partial M}{\partial \varphi} \\
\frac{\partial}{\partial \varphi}\left(\frac{1}{R} \frac{\partial M}{\partial \varphi}\right) & =N-R P_{r} .
\end{aligned}
$$

The strain $\varepsilon_{z 0}$ at the neutral axis and the cross-sectional curvature $k$ can be expressed as follows:

$$
\begin{aligned}
\varepsilon_{z 0} & =\frac{1}{R}\left(v^{\prime}+w\right) \\
k & =\frac{1}{R^{2}}\left(w^{\prime \prime}-v^{\prime}\right),
\end{aligned}
$$

where each prime denotes one differentiation with respect to $\varphi$.

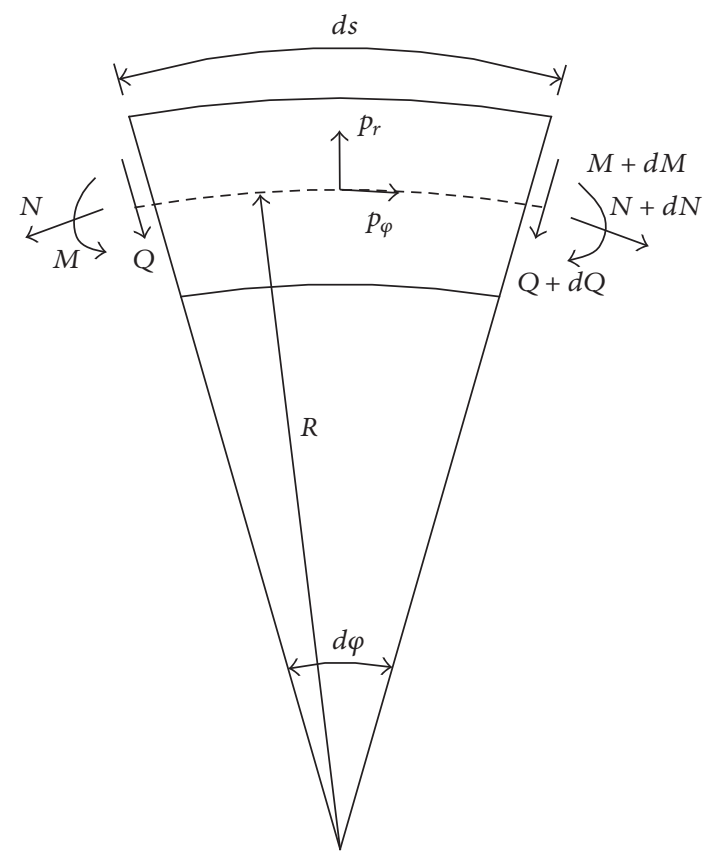

FIgURE 5: Force analysis of a microsegment.

The strain $\varepsilon_{z}$ at point $z$ can be given by

$$
\varepsilon_{z}=\frac{1}{1+z / R}\left(\varepsilon_{z 0}-z k\right)
$$

Putting (14), (20), and (21) together, the corresponding stress $\sigma_{z}$ could be obtained:

$$
\sigma_{z}=\frac{E(x, y, z)}{1+z / R}\left[\frac{1}{R}\left(v^{\prime}+w\right)-\frac{z}{R^{2}}\left(w^{\prime \prime}-v^{\prime}\right)\right]
$$


$N=\int_{A} \sigma_{z} d A, M=\int_{A} \sigma_{z} z d A$; then, substituting (22) into the expressions of $N, M$, respectively, yields

$$
\begin{aligned}
N= & \int_{A} \frac{E(x, y, z)}{1+z / R}\left[\frac{1}{R}\left(v^{\prime}+w\right)-\frac{z}{R^{2}}\left(w^{\prime \prime}-v^{\prime}\right)\right] d A \\
= & \left(v^{\prime}+w\right) \int_{A} \frac{E(x, y, z)}{R+z} d A \\
& -\left(w^{\prime \prime}-v^{\prime}\right) \int_{A} \frac{E(x, y, z)}{R^{2}+R z} z d A
\end{aligned}
$$

$M$

$$
\begin{aligned}
= & \int_{A} \frac{E(x, y, z) z}{1+z / R}\left[\frac{1}{R}\left(v^{\prime}+w\right)-\frac{z}{R^{2}}\left(w^{\prime \prime}-v^{\prime}\right)\right] d A \\
= & \left(v^{\prime}+w\right) \int_{A} \frac{E(x, y, z)}{R+z} z d A \\
& -\left(w^{\prime \prime}-v^{\prime}\right) \int_{A} \frac{E(x, y, z)}{R^{2}+R z} z^{2} d A .
\end{aligned}
$$

Let $k_{1}=\int_{A} E(x, y, z) /(1+z / R) d A, k_{2}=\int_{A} E(x, y, z) z /$ $(1+z / R) d A$, and $k_{3}=\int_{A} E(x, y, z) z^{2} /(1+z / R) d A$, so (23) could be simplified as follows:

$$
\begin{aligned}
& N=\frac{k_{1}}{R}\left(v^{\prime}+w\right)-\frac{k_{2}}{R^{2}}\left(w^{\prime \prime}-v^{\prime}\right) \\
& M=\frac{k_{2}}{R}\left(v^{\prime}+w\right)-\frac{k_{3}}{R^{2}}\left(w^{\prime \prime}-v^{\prime}\right) .
\end{aligned}
$$

The small vibration hypothesis with the usual sinusoidal expressions for deflections could be given by the following:

$$
\begin{gathered}
w=W \sin (\omega t) \\
v=V \sin (\omega t),
\end{gathered}
$$

where $W$ and $V$ are the amplitudes of $w$ and $v$, respectively.

Then translator inertia forces at the instant of maximum deflection are given as follows

$$
\begin{aligned}
& P_{\varphi}=m \omega^{2} V \\
& P_{r}=m \omega^{2} W,
\end{aligned}
$$

where $m$ is the mass per unit length of the beam and $\omega=2 \pi f$ is angular frequency, with $f$ being the frequency.

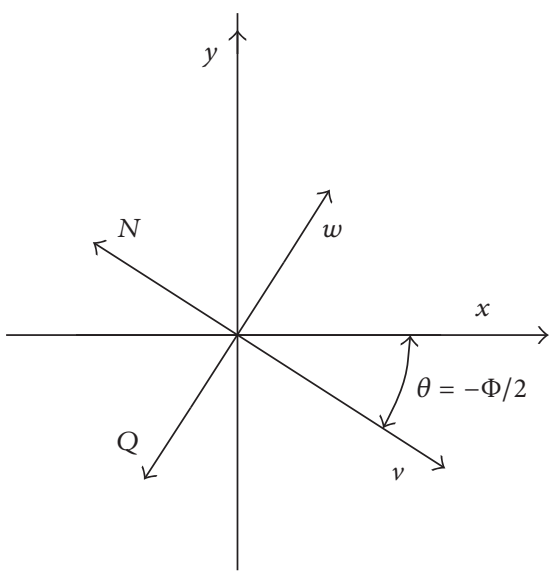

FIGURE 6: Coordinating relations for the right boundary.

Substituting (24), (25), (26a) and (26b), and (27a) and (27b) into (19), the dynamic equations can be obtained:

$$
\begin{aligned}
& V^{\prime \prime}= \frac{C_{1}}{C_{1}+C_{2}} W^{\prime \prime \prime}-\frac{C_{2}}{C_{1}+C_{2}} W^{\prime}-\frac{m R \omega^{2}}{C_{1}+C_{2}} V \\
& \frac{k_{1} k_{3}-k_{2}^{2}}{R^{4} C_{2}} W^{(4)} \\
&=\left[\frac{2 k_{2}}{R^{2}}-\frac{C_{1}}{C_{2}}\left(\frac{k_{1}}{R}-\frac{k_{2}}{R^{2}}\right)\right] W^{\prime \prime} \\
& \quad+\left[m R \omega^{2}-\frac{k_{1}}{R}+\frac{C_{1}}{C_{2}}\left(m R \omega^{2}-\frac{k_{1}}{R}\right)\right] W \\
& \quad-\left(\frac{C_{1}}{C_{2}} m R \omega^{2}+C_{1}+C_{2}\right) V^{\prime \prime},
\end{aligned}
$$

where $C_{1}=k_{2} / R^{2}+k_{3} / R^{3}, C_{2}=k_{1} / R+k_{2} / R^{2}$. In (28a) and (28b), the deflection and the uneven distribution of the elastic modulus caused by temperature gradient are taken into account.

By taking the coordinate relations shown in Figure 6, the boundary conditions in Figure 4 can be obtained:

$$
\begin{array}{r}
w \cos (\theta)+v \sin (\theta)=0 \\
N \cos (\theta)-Q \sin (\theta)+k_{t} \delta_{x}=0 \\
M=0,
\end{array}
$$

where $k_{t}$ is the spring stiffness, $\theta=-\Phi / 2, \delta_{x}=v \cos (\theta)-$ $w \sin (\theta)$.

Substituting (25) into (18) gives

$$
Q=\frac{k_{2}}{R^{2}}\left(v^{\prime \prime}+w^{\prime}\right)-\frac{k_{3}}{R^{3}}\left(w^{\prime \prime \prime}-v^{\prime \prime}\right) .
$$

Then, substituting (24), (25) ((26a) and (26b)), and (30) into (29a), (29b), and (29c) leads to the general expressions 


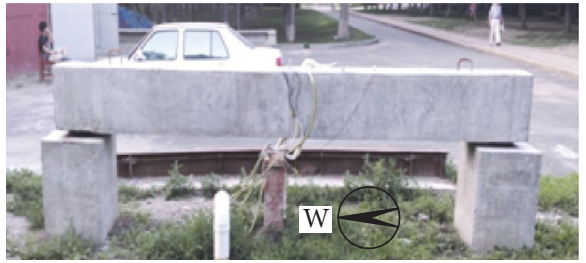

(a) The RC beam

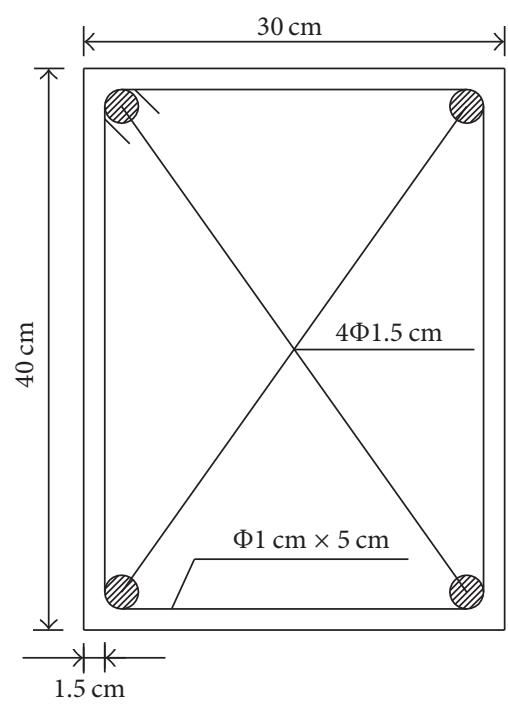

(b) Steel bar layout

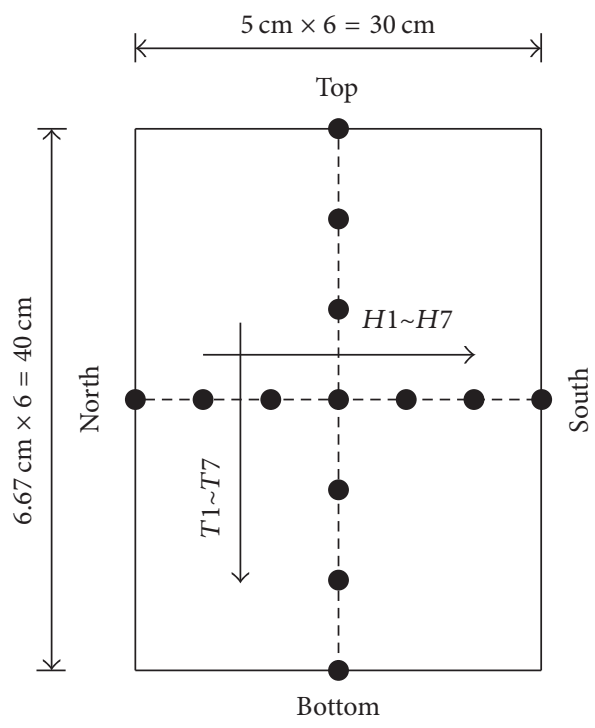

(c) Thermocouples layout

Figure 7

for the boundary conditions, that is,

$$
\begin{aligned}
& W \cos (\theta)+V \sin (\theta)=0 \\
& k_{t} \cos (\theta) V+\left(\frac{k_{1}}{R} \cos (\theta)+\frac{k_{2}}{R^{2}} \cos (\theta)\right) V^{\prime} \\
& +\left(\frac{k_{2}}{R^{2}} \sin (\theta)+\frac{k_{3}}{R^{3}} \sin (\theta)\right) V^{\prime \prime \prime} \\
& +\left(\frac{k_{1}}{R} \cos (\theta)-k_{t} \sin (\theta)\right) W-\frac{k_{2}}{R^{2}} \sin (\theta) W^{\prime} \\
& \quad-\left(\frac{k_{2}}{R^{2}} \cos (\theta)-\frac{k_{3}}{R^{3}} \sin (\theta)\right) W^{\prime \prime \prime}=0 \\
& W^{\prime \prime}-\left(\frac{k_{2} R}{k_{3}}+1\right) V^{\prime}=0 .
\end{aligned}
$$

By substituting $\theta=\Phi / 2$ and $\theta=-\Phi / 2$ into (31a), (31b), and (31c), respectively, the left and right boundary conditions can be obtained.

The spring stiffness $k_{t}$ actually includes the shear stiffness of bearing and constraint of surrounding structure. While only considering the effect of the shear stiffness of bearing, $k_{t}$ could be given by

$$
k_{t}=\frac{G_{b} A_{b}}{h_{b}},
$$

where $G_{b}$ is the shear modulus of bearing, $A_{b}$ is the area of bearing, and $h_{b}$ is the height of bearing.

Putting (28a) and (28b) and (31a), (31b), and (31c) together, the modal characteristics of simply supported beam under the effect of temperature could be solved. In general, the dynamic equations ((28a) and (28b)) are nonlinear with variable coefficients and could be solved by using the Multiple Shooting method [41].

\section{Laboratory Experiment}

4.1. Description of the Experiment. A laboratory experiment on a $400 \mathrm{~cm} \times 30 \mathrm{~cm} \times 40 \mathrm{~cm}$ reinforced concrete beam constructed on 25 June, 2015 (in Figure 7(a)), was carried out. The two ends of the test beam are placed on two precast concrete foundations, respectively, in which a $15 \mathrm{~cm}$ vacant is left at each end and the calculation span of beam is $370 \mathrm{~cm}$. The circular plate type rubber bearings are used as supports. Grade C40 was selected in accordance with the design code in China [42]. $\Phi 15 \mathrm{~mm}$ reinforced bars at a $15 \mathrm{~mm}$ interval were chosen for positive reinforcement with $15 \mathrm{~mm}$ cover and $\Phi 10 \mathrm{~mm}$ reinforced bars at a $200 \mathrm{~mm}$ interval were laid in the perpendicular direction (in Figure 7(b)).

As the length of beam is much larger than its height and width and solar intensity along the length direction of beam is uniform, temperature could be assumed to be uniformly distributed in the length direction. 7 thermocouples were placed in the mid-span along the directions of north-south and topbottom, respectively (in Figure 7(c), where denotes one thermocouple). An additional thermocouple was employed to measure the air temperature.

A 24-hour experiment from 8:00 am on 18 September 2016 was carried out. The beam was excited by an impact hammer and the vibration responses were recorded by 2 accelerometers at the positions of 3/10 span and mid-span. Meanwhile, the temperatures were automatically recorded from the embedded thermocouples every $1 \mathrm{~min}$ and solar intensity was measured and recorded every one hour. In the process of the experiment, from 9:00 am to 5:00 pm, the test 
TABLE 1: Solar intensity at different positions and times.

\begin{tabular}{|c|c|c|c|c|}
\hline Time & $\begin{array}{l}\text { The top surface } \\
\left(\mathrm{W} / \mathrm{m}^{2}\right)\end{array}$ & $\begin{array}{l}\text { The bottom surface } \\
\left(\mathrm{W} / \mathrm{m}^{2}\right)\end{array}$ & $\begin{array}{l}\text { The south surface } \\
\left(\mathrm{W} / \mathrm{m}^{2}\right)\end{array}$ & $\begin{array}{l}\text { The north surface } \\
\left(\mathrm{W} / \mathrm{m}^{2}\right)\end{array}$ \\
\hline $8: 00 \mathrm{am}$ & 66.9 & 8.9 & 57.8 & 51.2 \\
\hline 9:00 am & 593.8 & 133.7 & 553.5 & 74.6 \\
\hline $10: 00 \mathrm{am}$ & 706.7 & 139.3 & 669.1 & 85.6 \\
\hline $11: 00 \mathrm{am}$ & 687.2 & 47.3 & 577.8 & 64.8 \\
\hline $12: 00 \mathrm{am}$ & 861.2 & 78.2 & 702.8 & 129.2 \\
\hline $1: 00 \mathrm{pm}$ & 779.2 & 42.4 & 675.4 & 138 \\
\hline $2: 00 \mathrm{pm}$ & 49.1 & 7.3 & 27.6 & 10.8 \\
\hline $3: 00 \mathrm{pm}$ & 437.4 & 57.8 & 404.6 & 61.8 \\
\hline $4: 00 \mathrm{pm}$ & 245.5 & 47.2 & 208.7 & 41 \\
\hline $5: 00 \mathrm{pm}$ & 25.6 & 5 & 23.2 & 7.6 \\
\hline 6:00 am & 14.8 & 2.1 & 8 & 5.6 \\
\hline 7:00 am & 33.4 & 6.2 & 30.5 & 16.6 \\
\hline $8: 00 \mathrm{am}$ & 46.4 & 10.2 & 48 & 20 \\
\hline
\end{tabular}

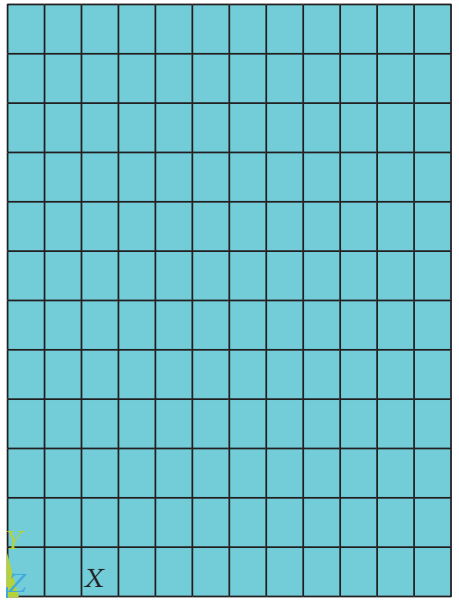

FIGURE 8: A two-dimensional transient heat conduction model.

beam was completely exposed to the sun except for the cloudy at 2:00 pm; the sun is blocked by the buildings after 5:00 pm. The test results of solar intensity are listed in Table 1.

According to (28a) and (28b), the temperature field of an entire structure is needed, but the experiment only got the temperature of 14 points. Therefore, a thermodynamic model is used here to predict the temperature distribution throughout the structure. Due to the uniform temperature along the length of beam, a two-dimensional transient heat conduction model is established by the plane temperature element Plane55 based on ANSYS software (in Figure 8). In the thermal analysis, the influences of heat flux exchange between beam and surrounding air, structural thermal radiation, and solar radiation should be taken into account. Therefore, the boundary conditions for energy exchange between surface of the beam and air are as follows:

$$
k \frac{\partial T}{\partial n}=h\left(T_{a}-T_{s}\right)+\alpha I
$$

where $k$ is the thermal conductivity, $T$ is the temperature, $T_{\alpha}$ is the ambient air temperature, $T_{s}$ is the surface temperature of the beam, $n$ is the normal to the surface, $h$ is the heat transfer coefficient, $\alpha$ is the absorptivity coefficient of the surface material, and $I$ is the irradiation.

Provided that $T_{a}^{*}=T_{a}+\alpha I / h$, the boundary conditions could be rewritten as follows:

$$
k \frac{\partial T}{\partial n}=h\left(T_{a}^{*}-T\right)
$$

In the thermal analysis, the parameters are given as $k=$ $2.5 \mathrm{~W} /\left(\mathrm{m} \cdot{ }^{\circ} \mathrm{C}\right)$; the heat transfer coefficients of the bottom surface, the top surface, the south surface, and the north surface are $h_{b}=6.5, h_{t}=21, h_{s}=15, h_{n}=10 \mathrm{~W} /\left(\mathrm{m}^{2} \cdot{ }^{\circ} \mathrm{C}\right)$, respectively, the specific heat capacity $C=970 \mathrm{~J} /\left(\mathrm{kg} \cdot{ }^{\circ} \mathrm{C}\right) ; \alpha=$ 0.5 ; the density of concrete $\rho=2548 \mathrm{~kg} / \mathrm{m}^{3}$. There are two steps for the thermal analysis: firstly, the steady-state analysis of time interval (i.e., $t=0.01 \mathrm{~s}$ ) is performed based on the measured temperature data at 8:00 am; secondly, the transient analysis with 4-minute time step is carried out. Then, the temperature fields at different times could be calculated; for example, the temperature cloud chart at 2:00 pm is shown in Figure 9. The calculation and test results of temperature at positions $T 1, T 4, T 6, H 2$, and $H 5$ in Figure 7 (c) are shown in Figure 10, which indicate a good agreement between the two results. Therefore, the thermal analysis model can be employed to predict the temperature distribution of beam.

For an illustrative purpose, the every 4-hour results of $T 1$ to $T 7$ are shown in Figure 11, which present that the temperature distribution along the $z$-axis direction is nonuniform and nonlinear.

\subsection{Comparative Analysis between Theoretical and Test Results}

4.2.1. The Influence of Temperature on Natural Frequency. According to the temperature field obtained by the thermal analysis and the relationship between the elastic modulus and 


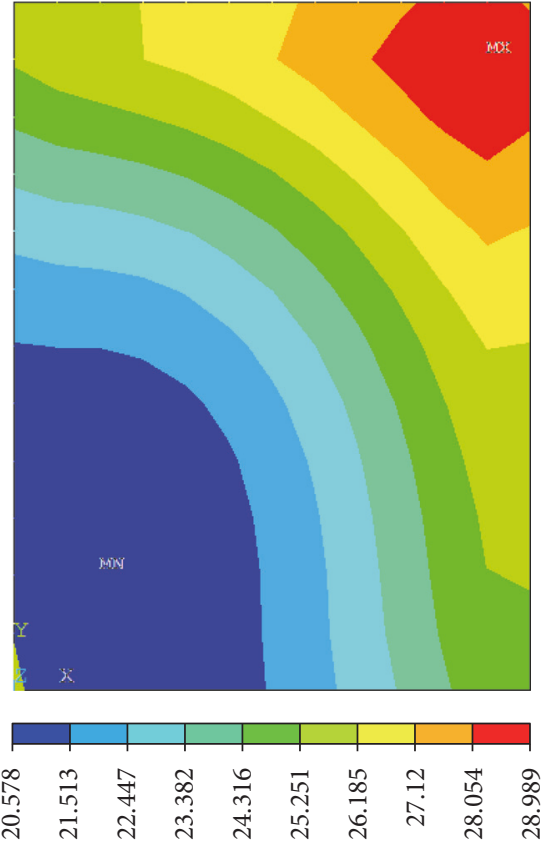

FIGURE 9: The temperature cloud chart at 2:00 pm.

temperature in (14), the modal characteristics of beam could be calculated by solving the dynamic equations in (28a) and (28b).

Meanwhile, the test modal characteristics were obtained through modal testing and modal analysis. Firstly, about 24second acceleration signal of a $5120 \mathrm{~Hz}$ sampling rate was obtained through 1\# and 2\# accelerometers (Figure 12 shows the acceleration time-history curves on 18 September 2016 at 8:00 am), which are located at mid-span and 3/10 span, respectively. Secondly, the empirical mode decomposition (EMD) [43] was used to decompose the data into many intrinsic mode function (IMF) components. The lowest three IMFs on 18 September 2016 at 8:00 am are shown in Figure 13. Finally, each IMF was analyzed by Hilbert transform to obtain the corresponding time-varying frequencies as shown in Figure 14. Due to the relatively short time of test as well as amplitude attenuation, the frequencies did not change significantly over time as illustrated in Figure 14.

The test and calculation results of the first three frequencies at different times are presented in Table 2.

From Table 2, the test frequencies are reasonably close to the calculation frequencies, especially for the 1st frequency, and the largest deviation between the test and calculation results of the 2 nd frequency is about $19 \%$. The reasons for this phenomenon may be the following two aspects: (1) the boundary conditions of the test beam may be different from that of the simply supported beam; (2) the geometrical properties of the test beam (the depth-span ratio is $0.4 / 3.7$ ) may be not fully consistent with the Euler-Bernoulli beam theory, in which the moment of inertia and shear deformation will have an influence on modal characteristics of beam. However, this paper did not update calculation model to match the measurement, which will be the focus of the future research about Timoshenko beams under the effect of temperature. Therefore, to validate the proposed method, the variation ratios of frequency (FVR) between test and calculation results are compared and plotted in Figure 15. FVR is defined as

$$
\mathrm{FVR}=\frac{\omega_{i}}{\omega_{0}} \times 100 \%
$$

where $\omega_{i}$ is the frequency at time $i$ and $\omega_{0}$ is the frequency at initial time, that is, 8:00 am on 18 September.

Figure 15 shows that the frequency varies with time and the first three test frequencies change up to $2.80 \%, 2.93 \%$, and $2.86 \%$ in a 24 -hour period, respectively. In [25], when the structure was destroyed, the variation of natural frequency is only $10 \%$. Therefore, it is clear that the change of environmental conditions has a great influence on frequency of beam. The errors between the test and calculation results of the first three frequencies at the same moment increase with modal order and the maximum errors are only $0.54 \%, 0.83 \%$, and $0.91 \%$, respectively, which verifies that the proposed method possessed favorable accuracy. In addition, it is noted that FVR reached the maximum value at about 2:00 pm. This is because, at this time, the temperature of beam reached the maximum value (in Figure 10) and the temperature distribution was quite uneven (in Figure 11).

4.2.2. The Influence of Temperature on Modal Shape. The first three modal shapes of beam at different times can be calculated by the proposed method and shown in Figure 16.

From Figure 16, the first three radial modal shapes at different times are basically unchanged. However, the tangential and rotational modal shapes have obvious changes especially at about 1:00 pm, which is because the deflection of beam caused by temperature gradient is rather larger with respect to other times. In view of vibration amplitude among the radial, tangential, and rotational vibration, the vibration of beam is mainly based on the radial vibration and the tangential and rotational vibrations have less influence on the beam. Due to the smaller deflection of beam caused by temperature, the modal shapes of the test beam are close to those of straight beams, as shown in Figures 16(a), 16(d), and 16(g).

\subsubsection{The Influence of Boundary Conditions on Natural} Frequency. The ratio of change for the first three natural frequencies of beam under different shear stiffness of bearing $k_{t}$ could be calculated by the proposed method and shown in Figure 17.

As seen in Figure 17, the ratio of change increases with the shear stiffness of bearing and tends to be stable when the shear stiffness less than $1 \times 10^{8} \mathrm{~N} / \mathrm{m}$ or more than $1 \times$ $10^{12} \mathrm{~N} / \mathrm{m}$. Besides, the ratio of change at about 2:00 pm is larger than others, which is because the temperatureinduced deflection at this time is rather larger with respect to other times. From the above analysis, we can conclude that the influence of the shear stiffness of bearing on modal characteristics increases with the deflection of beam increasing. Nevertheless, due to the smaller temperature-induced deflection making the test beam in this study close to a 

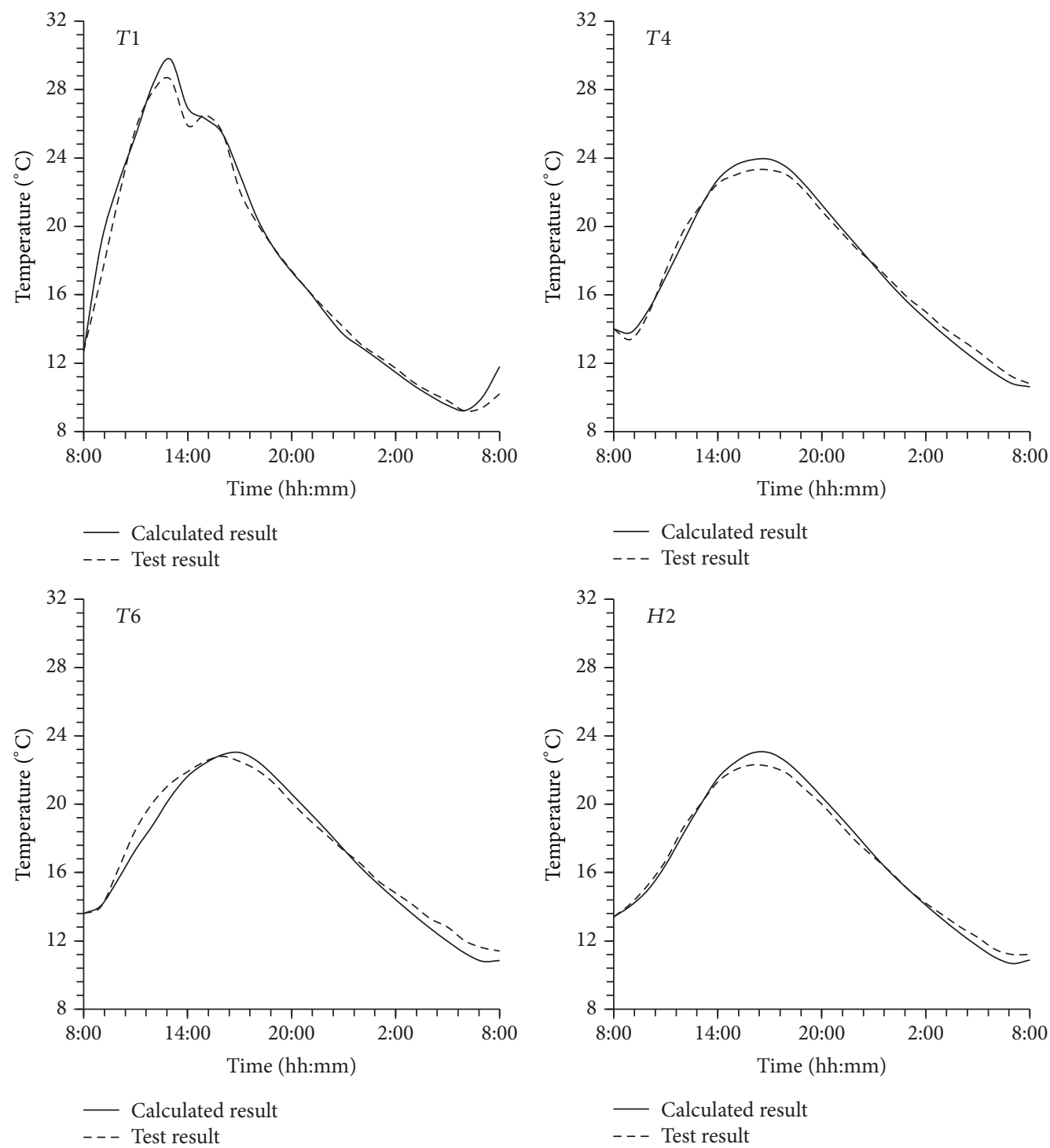

- Calculated result

- - - Test result

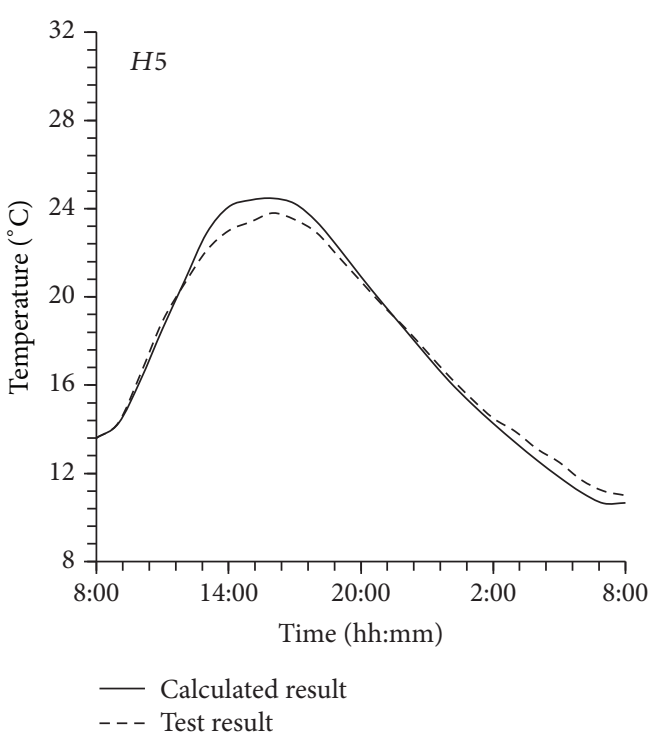

FIGURE 10: Comparison of temperature data in a 24-hour period: calculated and test results. 

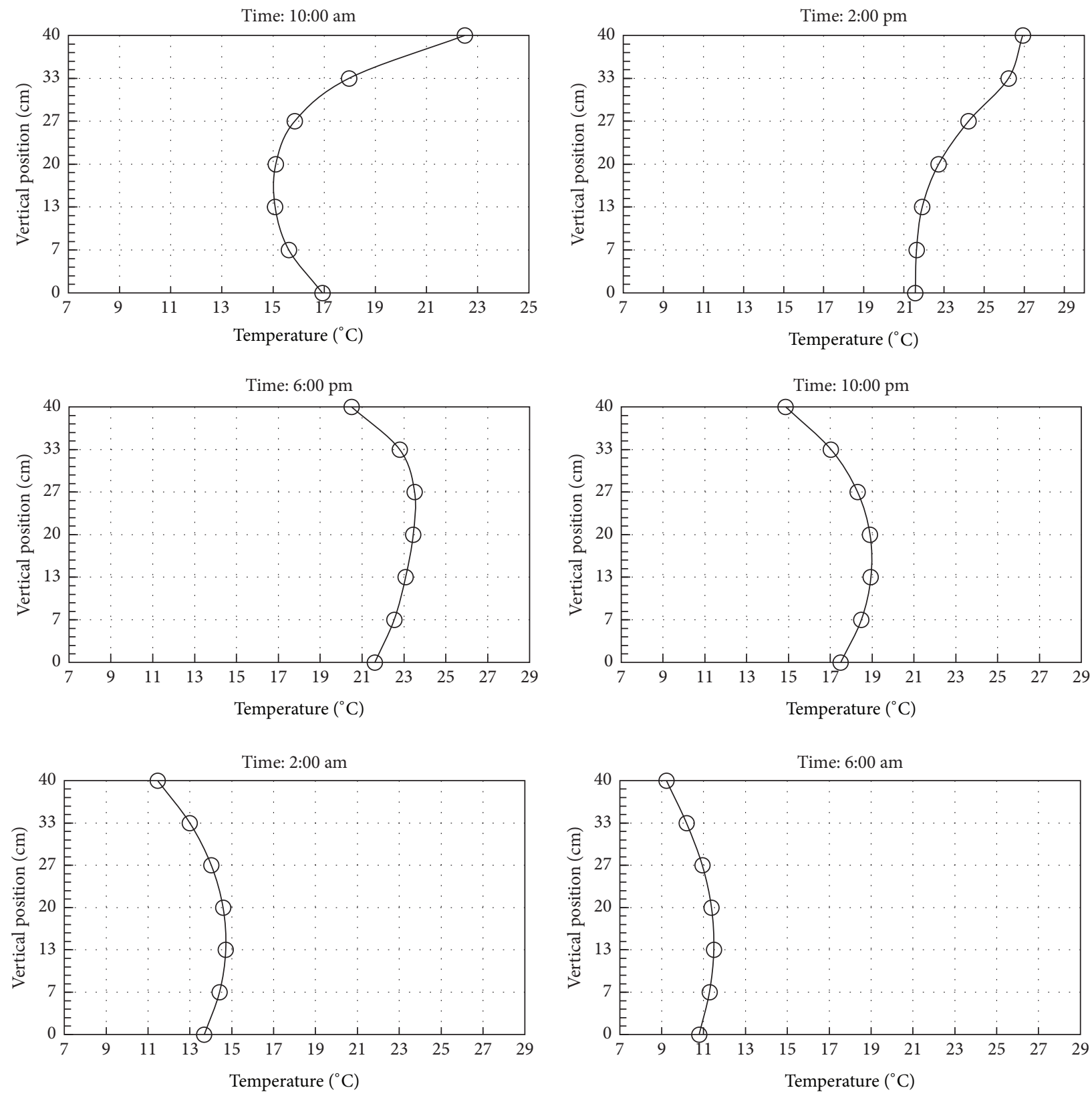

FIGURE 11: Temperature distribution along the $z$-axis direction at different times.

straight beam, the shear stiffness of bearing has little influence on natural frequencies of beam.

From the above observations and analysis, temperature will change both the structural deflection and the elastic modulus of concrete. Due to the smaller deflection caused by temperature, the test beam is close to a straight beam. The influence of structural deflection on modal characteristics is rather smaller than that of elastic modulus. Hence, it can be concluded that the variation of elastic modulus by temperature is the main reason resulting in the changes of modal characteristics of the test beam, which is also obtained in [37]. When the structural span or cross-sectional height increases, the deflection of beam induced by temperature will become larger, especially for the steel and concrete composite structure, and the deflection will make the ratio of change of natural frequencies increase in accordance with [35]. Moreover, if the structure has a precamber or a certain deflection, the influence of the deflection caused by temperature and the stiffness of bearing on modal characteristics will be more obvious and the related research is ongoing.

\section{Application to a Real Structure}

Figure 18 shows a south-north bridge of Anlongquan intercommunication overpass on 102 national highway. The construction of this bridge was started in 2010 and completed 
TABLE 2: Test and calculation results of the first three frequencies at different times.

\begin{tabular}{|c|c|c|c|c|c|c|}
\hline \multirow{2}{*}{ Time } & \multicolumn{2}{|c|}{ 1st frequency } & \multicolumn{2}{|c|}{ 2nd frequency } & \multicolumn{2}{|c|}{ 3rd frequency } \\
\hline & Calculation & Test & Calculation & Test & Calculation & Test \\
\hline $8: 00$ & 48.47 & 51.25 & 193.89 & 157.19 & 436.25 & 501.87 \\
\hline $9: 00$ & 48.20 & 51.05 & 192.79 & 156.30 & 433.79 & 500.62 \\
\hline $10: 00$ & 47.92 & 50.94 & 191.67 & 156.68 & 431.27 & 498.61 \\
\hline $11: 00$ & 47.68 & 50.63 & 190.72 & 155.90 & 429.13 & 493.13 \\
\hline $12: 00$ & 47.46 & 50.31 & 189.84 & 154.47 & 427.16 & 491.88 \\
\hline $13: 00$ & 47.27 & 50.12 & 189.08 & 153.45 & 425.45 & 488.44 \\
\hline $14: 00$ & 47.29 & 50.17 & 189.17 & 153.90 & 425.65 & 490.00 \\
\hline $15: 00$ & 47.32 & 49.82 & 189.29 & 152.59 & 425.91 & 488.13 \\
\hline $16: 00$ & 47.33 & 50.00 & 189.31 & 152.99 & 425.95 & 487.50 \\
\hline $17: 00$ & 47.43 & 50.00 & 189.70 & 152.93 & 426.84 & 488.75 \\
\hline $18: 00$ & 47.59 & 50.23 & 190.36 & 153.70 & 428.33 & 490.00 \\
\hline 19:00 & 47.74 & 50.31 & 190.97 & 154.83 & 429.70 & 490.94 \\
\hline $20: 00$ & 47.88 & 50.74 & 191.51 & 155.93 & 430.90 & 492.81 \\
\hline 21:00 & 47.99 & 50.74 & 191.98 & 155.70 & 431.96 & 493.44 \\
\hline $22: 00$ & 48.12 & 50.63 & 192.48 & 155.03 & 433.09 & 494.06 \\
\hline 23:00 & 48.25 & 50.94 & 192.99 & 155.94 & 434.22 & 495.00 \\
\hline $0: 00$ & 48.35 & 50.94 & 193.39 & 156.55 & 435.13 & 497.00 \\
\hline $1: 00$ & 48.43 & 51.15 & 193.74 & 157.15 & 435.92 & 500.00 \\
\hline $2: 00$ & 48.52 & 51.45 & 194.09 & 158.30 & 436.71 & 501.00 \\
\hline $3: 00$ & 48.61 & 51.56 & 194.43 & 158.53 & 437.47 & 501.25 \\
\hline $4: 00$ & 48.68 & 51.56 & 194.74 & 157.67 & 438.17 & 501.56 \\
\hline $5: 00$ & 48.75 & 51.75 & 195.02 & 158.45 & 438.79 & 501.88 \\
\hline $6: 00$ & 48.81 & 51.75 & 195.24 & 158.12 & 439.30 & 503.44 \\
\hline $7: 00$ & 48.80 & 51.75 & 195.22 & 158.57 & 439.25 & 503.43 \\
\hline $8: 00$ & 48.71 & 51.66 & 194.84 & 157.89 & 438.39 & 503.63 \\
\hline
\end{tabular}

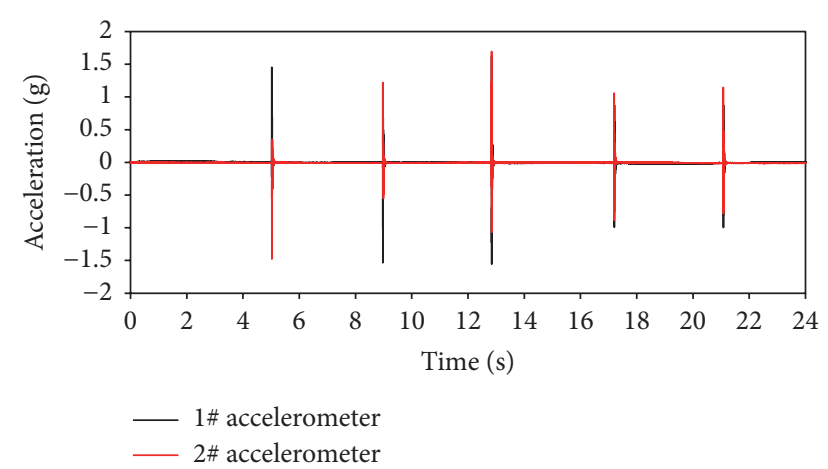

FIgURE 12: Acceleration time-history curves on 18 September 2016 at 8:00 am.

in 2013. It is a simply supported bridge with $25 \mathrm{~m}$ span and the superstructure is a two-cell box girder. Relied on Science and Technology Project of Jilin Province "The Health Monitoring Technology Research on the Anlongquan Interchange Overpass of 102 National Highway," Professor Cheng has carried out two aspects of research on this bridge. The first aspect is long-term condition monitoring of structural creep and concrete shrinkage on the bridge. The second aspect is to monitor and evaluate the condition of the bridge in real time through test strain data. Therefore, only the fiber grating temperature and strain sensors were embedded in advance in the bridge and no real-time dynamic characteristics testing equipment were preinstalled on the structure. In order to verify the accuracy of the bridge state evaluation technique developed based on strain monitoring data, Professor Cheng's group conducted 8 times static load and dynamic load tests in April 2015 and provided these dynamic test data for this article.

There are 9 temperature sensors (numbering $T_{1}-T_{9}$ ) embedded in advance in the mid-span cross section of bridge as illustrated in Figure 18. The layout of the temperature sensors is presented in Figure 19, $T_{1}, T_{4}$, and $T_{7}$ for the roof temperature measurement, $T_{3}, T_{6}$, and $T_{9}$ for the floor temperature measurement, $T_{2}, T_{5}$, and $T_{8}$ for the webs temperature measurement. During the monitoring of this bridge, temperature has been measured continuously by FBG-8600 

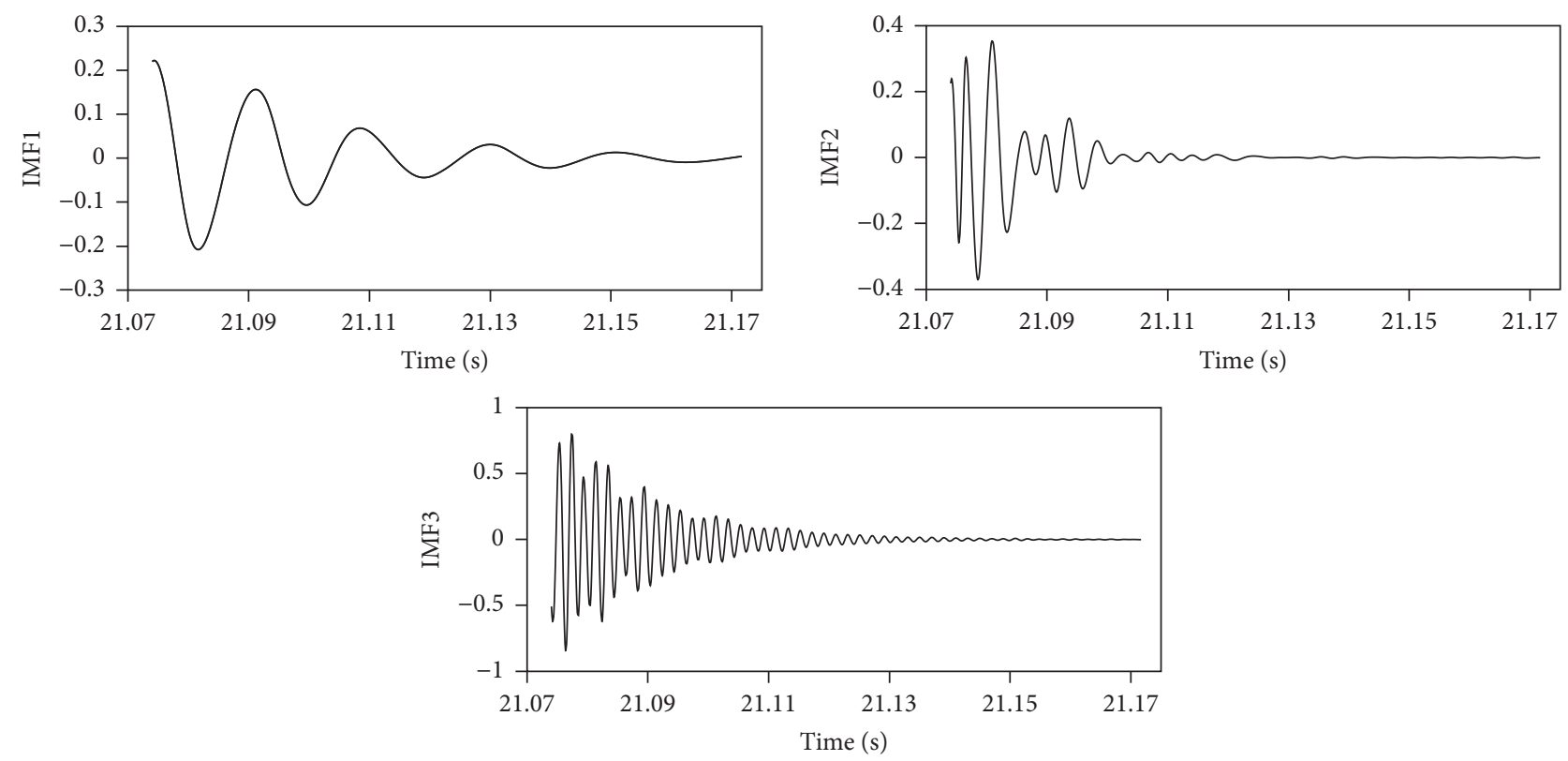

FIGURE 13: The lowest three IMFs on 18 September 2016 at 8:00 am.
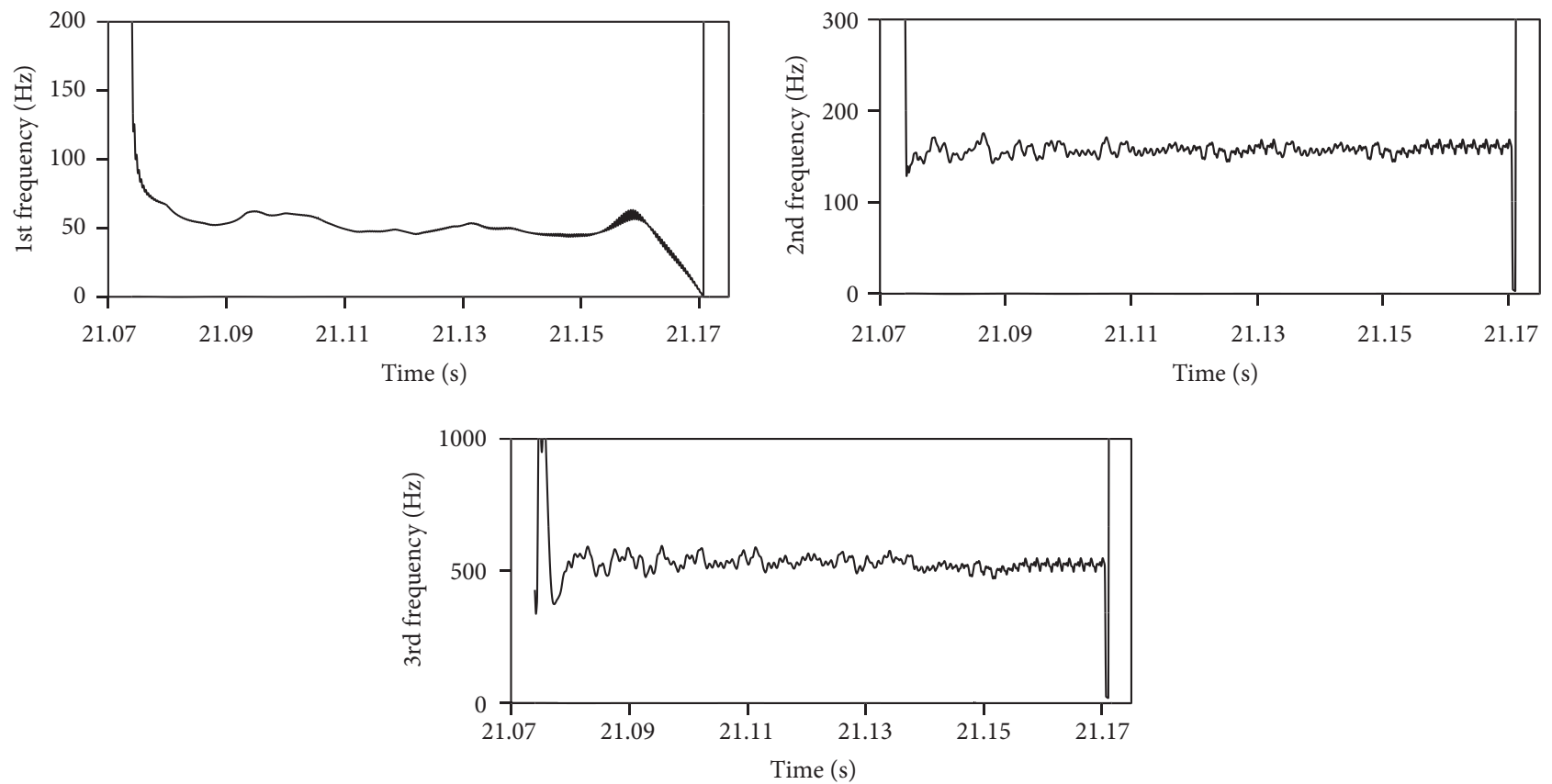

FIGURE 14: The lowest three frequencies on 18 September 2016 at 8:00 am.

high-speed fiber grating demodulator and recorded from 9 April to 3 September 2015. Figure 20 shows information of 30000 collected wavelengths from 3:00 pm on 9 April 2015. Then, time-varying temperature could be obtained by FBG8600 data center software. The corresponding test results of $T_{1}-T_{9}$ at the time of the modal test were extracted as shown in Table 3.
As for the modal test, nine DH610 accelerometers (including two fulcrums) were equidistantly arranged on one side of the bridge. A two-axle vehicle passed through a six $\mathrm{cm}$ high wedge block located at 1/4 span of the bridge. Meanwhile DH5922 system produced by DongHua Testing Technology Company Limited samples about 6-second data from the nine accelerometers at a $512 \mathrm{~Hz}$ sampling rate. The 


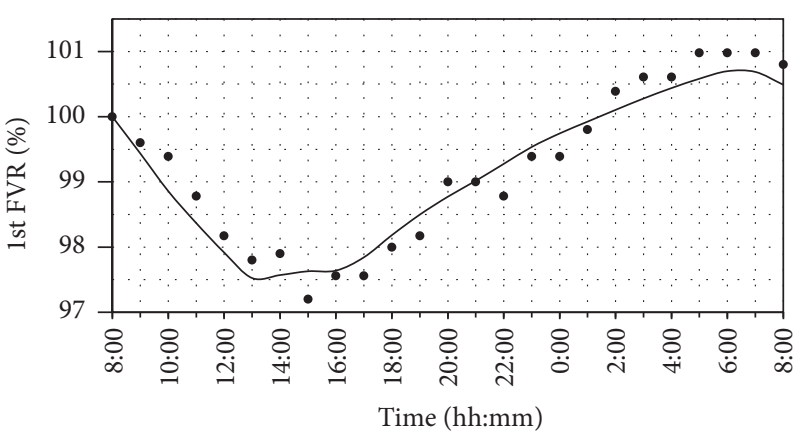

- Calculated values

- Test values

(a) 1st natural frequency

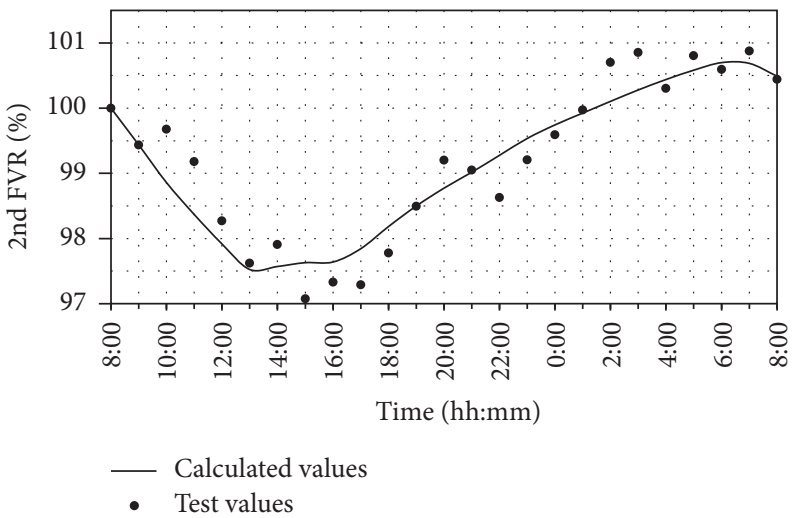

(b) 2nd natural frequency

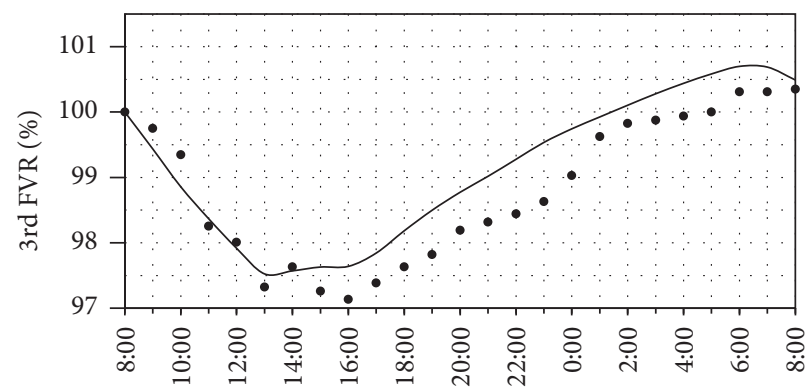

Time (hh:mm)

- Calculated values

- Test values

(c) 3rd natural frequency

FIGURE 15: Comparison of FVR between test and calculation results at different times.

TABLE 3: The results from $T_{1}$ to $T_{9}$ at different times.

\begin{tabular}{|c|c|c|c|c|c|c|c|c|c|}
\hline \multirow{2}{*}{ Time } & \multicolumn{9}{|c|}{ Temperature $\left({ }^{\circ} \mathrm{C}\right)$} \\
\hline & $T_{1}$ & $T_{2}$ & $T_{3}$ & $T_{4}$ & $T_{5}$ & $T_{6}$ & $T_{7}$ & $T_{8}$ & $T_{9}$ \\
\hline 4/09/2015 15:12:38 & 15.2 & 18.5 & 18.2 & 8.3 & 11.7 & 14.4 & 11.9 & 9.9 & 16.1 \\
\hline 4/10/2015 09:05:39 & 6.6 & 7.2 & 8.3 & 6.5 & 9.9 & 12.0 & 6.4 & 7.7 & 10.3 \\
\hline 4/12/2015 08:10:59 & 4.8 & 4.5 & 5.2 & 5.1 & 9.4 & 8.8 & 5.0 & 6.3 & 7.0 \\
\hline 4/14/2015 19:02:56 & 17.1 & 16.5 & 14.8 & 11.3 & 15.3 & 16.8 & 14.1 & 13.8 & 15.8 \\
\hline 4/15/2015 20:00:05 & 23.1 & 22.5 & 21.5 & 15.7 & 20.3 & 22.0 & 19.4 & 18.1 & 21.9 \\
\hline 4/18/2015 18:04:13 & 15.5 & 14.2 & 13.5 & 14.0 & 16.2 & 18.7 & 14.8 & 14.9 & 16.0 \\
\hline 4/25/2015 18:27:42 & 23.1 & 24.6 & 23.8 & 19.4 & 22.4 & 25.1 & 21.2 & 21.5 & 24.6 \\
\hline 4/27/2015 15:01:31 & 28.5 & 33.6 & 35.6 & 25.2 & 28.2 & 30.7 & 26.8 & 26.9 & 33.0 \\
\hline
\end{tabular}

modal frequencies are calculated and extracted by frequency spectrum analysis using fast Fourier transform (FFT). The mid-span and $1 / 4$ span time history of acceleration signal and corresponding amplitude spectrum at 15:12 on 9 April 2015 are shown in Figure 21.

Based on the monitoring results of temperature listed in Table 3, the entire cross-sectional temperature could be estimated by using linear fit. The corresponding frequencies can be calculated by the proposed method and the calculation and test frequencies at different times are presented in Table 4. It can be seen that the calculation results are close to the test ones and the maximum error between the two is $2.6 \%$, which is less than that of the test beam. This is because the actual simply supported box-girder bridge is more consistent with Euler-Bernoulli beam theory relative to the test beam due to the geometrical properties. Besides, there are smaller 


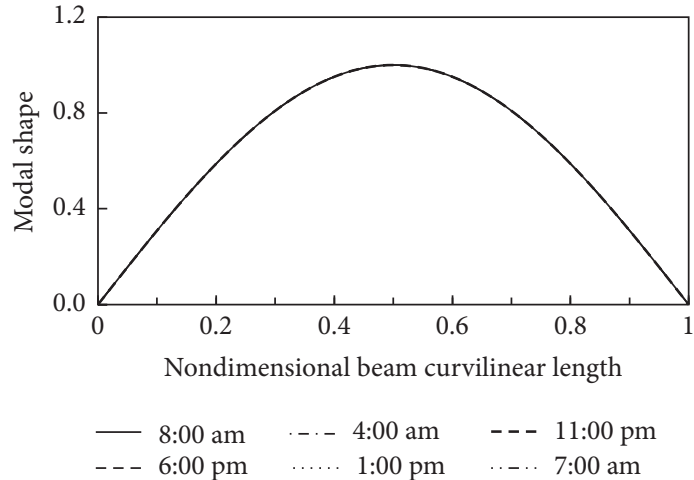

(a) 1st radial

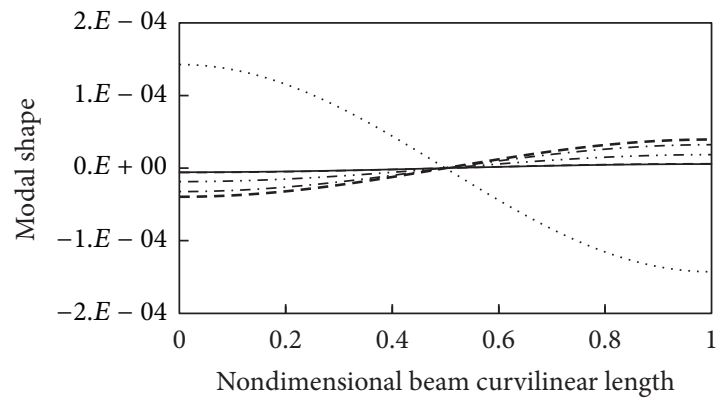

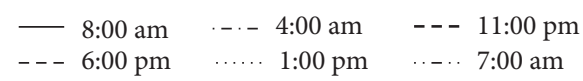

(c) 1st rotational

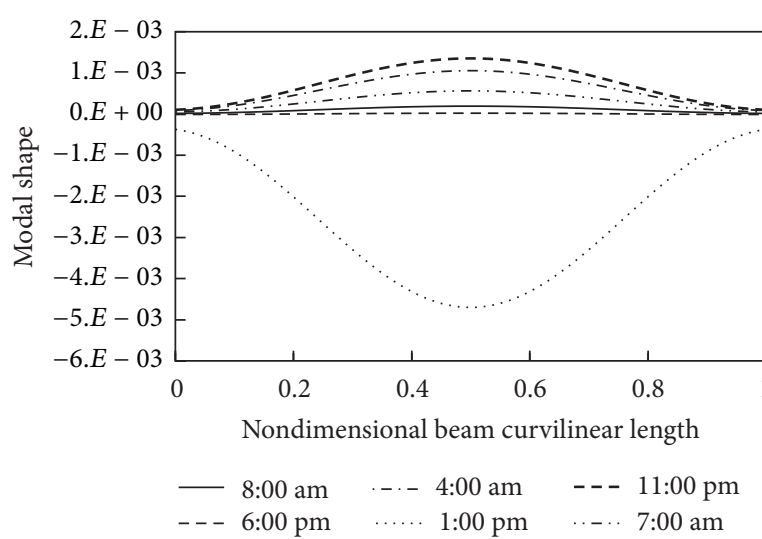

(e) 2nd tangential

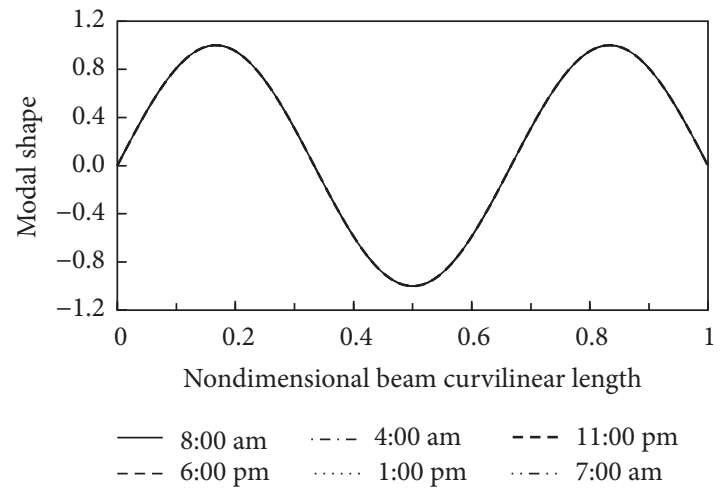

(g) 3rd radial

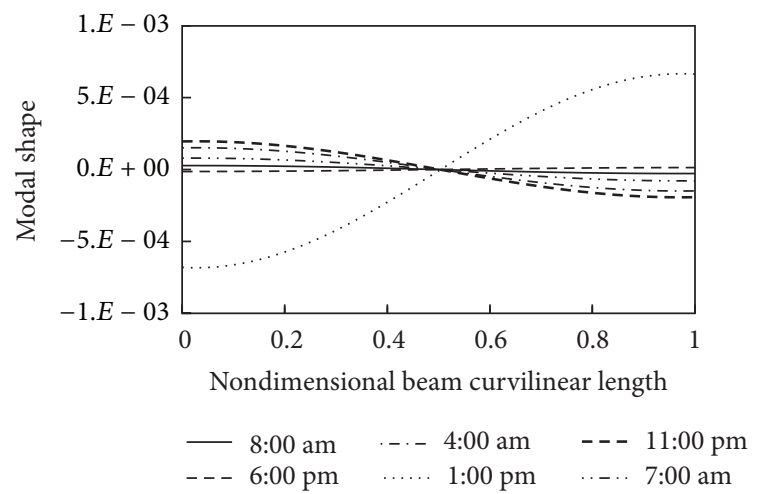

(b) 1st tangential

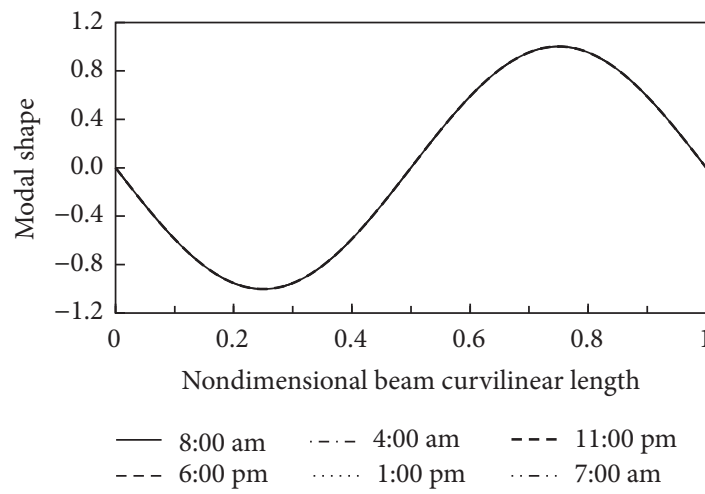

(d) 2nd radial

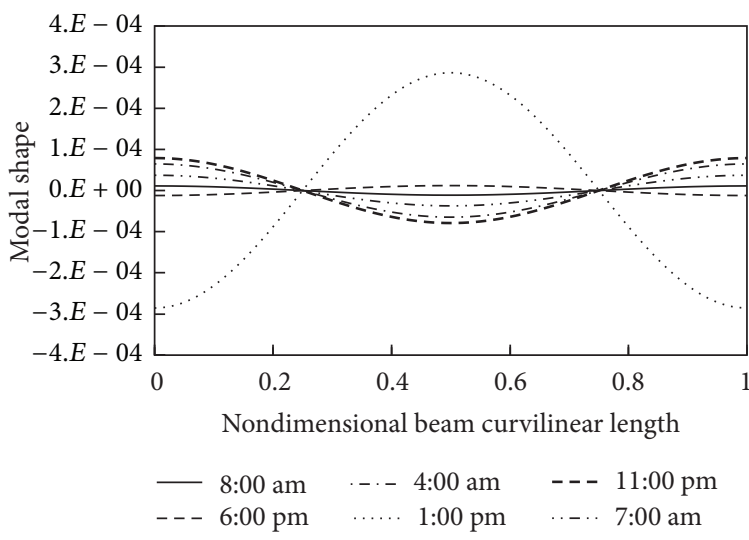

(f) 2nd rotational

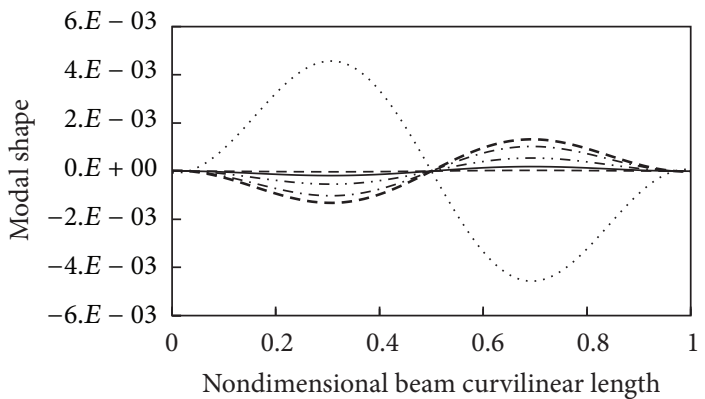

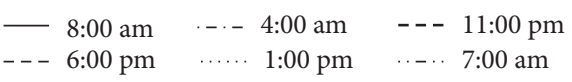

(h) 3rd tangential

Figure 16: Continued. 


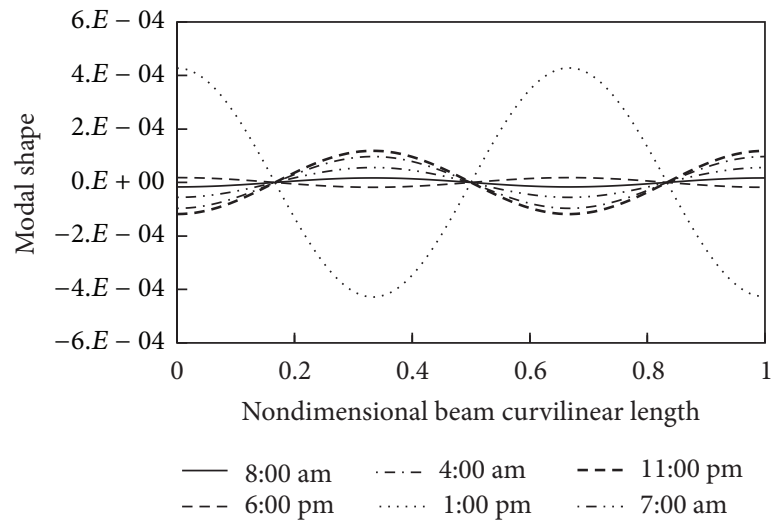

(i) 3rd rotational

FIGURE 16: The modal shapes at different times.

TABLE 4: Test and calculation frequencies at different times.

\begin{tabular}{cccccccccc}
\hline & Frequency results & $4 / 9$ & $4 / 10$ & $4 / 12$ & $4 / 14$ & $4 / 15$ & $4 / 18$ & $4 / 25$ & $4 / 27$ \\
\hline \multirow{4}{*}{1 st } & Calculation(Hz) & 6.21 & 6.29 & 6.32 & 6.20 & 6.12 & 6.19 & 6.09 & 5.99 \\
& FVR (\%) & 0.00 & 1.21 & 1.68 & -0.29 & -1.50 & -0.38 & -1.99 & -3.52 \\
& Test (Hz) & 6.35 & 6.41 & 6.44 & 6.32 & 6.24 & 6.31 & 6.20 & 6.12 \\
& FVR (\%) & 0.00 & 0.89 & 1.50 & -0.40 & -1.70 & -0.54 & -2.34 & -3.65 \\
& Dev (\%) & 2.19 & 1.87 & 2.01 & 2.07 & 1.98 & 2.02 & 1.82 & 2.05 \\
\hline \multirow{4}{*}{ 2nd } & Calculation(Hz) & 24.85 & 25.15 & 25.27 & 24.78 & 24.48 & 24.76 & 24.36 & 23.98 \\
& FVR (\%) & 0.00 & 1.21 & 1.68 & -0.29 & -1.50 & -0.38 & -1.99 & -3.53 \\
& Test (Hz) & 25.44 & 25.78 & 25.88 & 25.43 & 25.06 & 25.40 & 24.98 & 24.53 \\
& FVR (\%) & 0.00 & 1.33 & 1.71 & -0.07 & -1.50 & -0.17 & -1.82 & -3.58 \\
& Dev (\%) & 2.38 & 2.50 & 2.41 & 2.60 & 2.37 & 2.59 & 2.56 & 2.32 \\
\hline
\end{tabular}

Note . Dev $=($ Calculation - Test $) /$ Test $\times 100$; the first line in Table 4 represents the corresponding time in Table 3; for example, 4/9 represents 4/09/2015 15:12:38 in Table 3.

errors between FVR of the calculation and test results, which also reveals that the proposed method possessed favorable accuracy.

From Table 4, the 1st test frequency on $4 / 27$ is lower about $5.0 \%$ than that on $4 / 12$. In [1], it is pointed out that the natural frequency of simply supported beam decreased $5.6 \%$ at the condition of the cross-sectional stiffness decreasing $30 \%$. Then, it may be concluded that cross-sectional stiffness of the simply supported beam for monitoring decreases about $30 \%$, which is a wrong assessment conclusion obviously. This is because the influence of temperature on the test frequency has not been excluded in the assessment. The 1st calculation frequency on $4 / 27$ is lower about $5.2 \%$ than that on $4 / 12$, which is induced by temperature. By excluding the influence of temperature, the variation of 1st test frequency is rather small and only $0.2 \%$. Therefore, it can be deduced that the beam is not damaged, which could be validated with the results of static load test by Professor Cheng.

From the above analysis, the most notable advantage of the proposed method is to accurately calculate natural frequency of the simply supported beam caused by temperature.
It can make an accurate assessment for bridges by excluding the influence of temperature from the test frequencies.

\section{Conclusions and Need for Further Investigations}

This paper presented an approach for calculating modal characteristics of simply supported beam under the effect of temperature, in which the change of elastic modulus and deflection induced by temperature and shear stiffness of bearing were taken into account. Then, a laboratory experiment on a rectangular-sectional simply supported beam was conducted to verify the correctness of the proposed approach and the proposed method was applied to an actual simply supported box-girder bridge. The following conclusions can be drawn:

(1) There are some errors between the calculation and test results of the test beam, while these two of the actual simply supported box-girder bridge are in good agreement. This is because the actual simply supported box-girder bridge is 


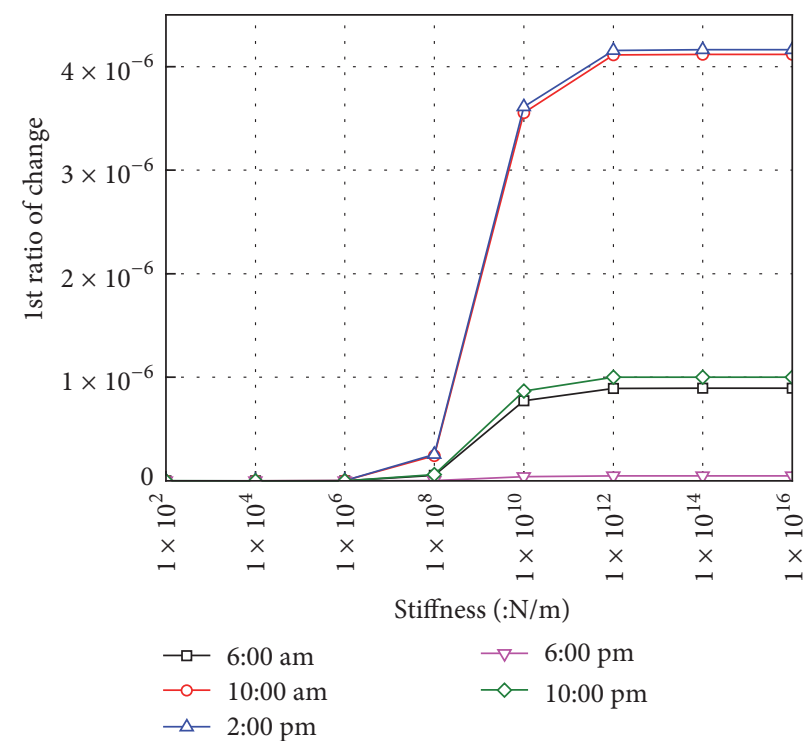

(a) 1st natural frequency

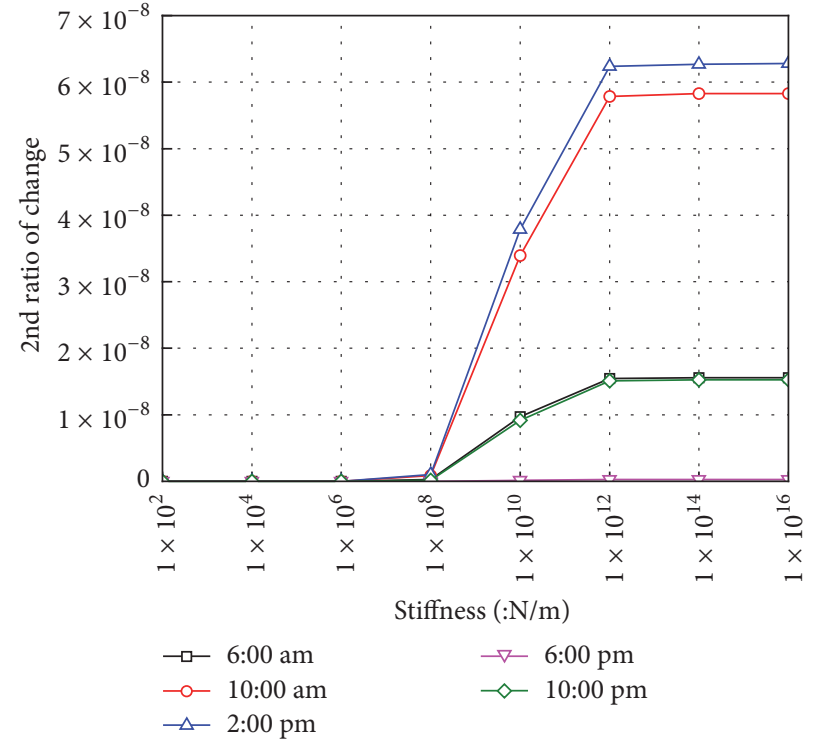

(b) 2nd natural frequency

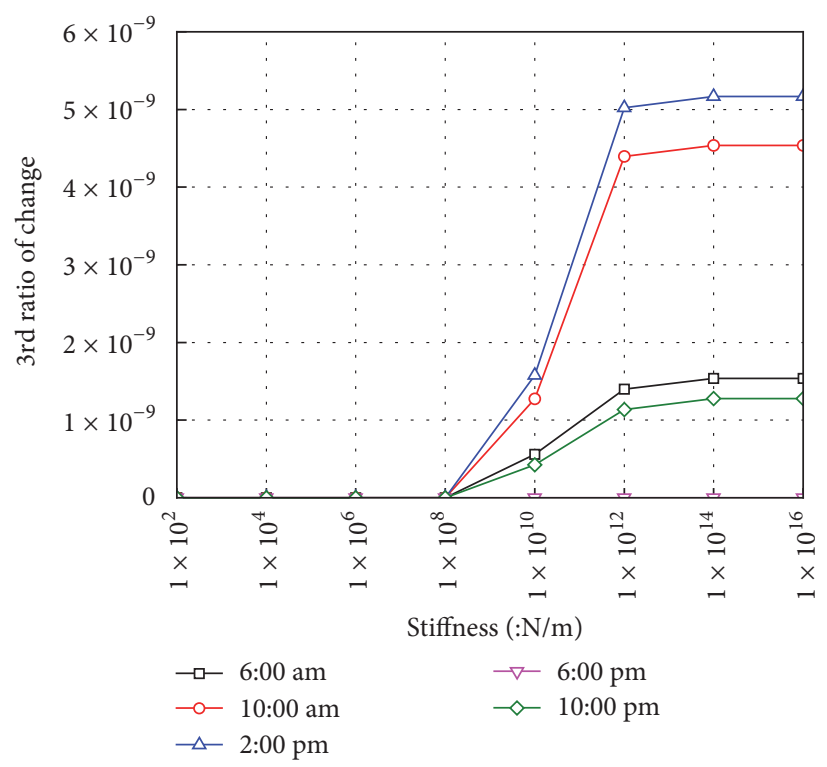

(c) 3rd natural frequency

FIGURE 17: The ratio of change for the first three natural frequencies of beam under different shear stiffness of bearing.

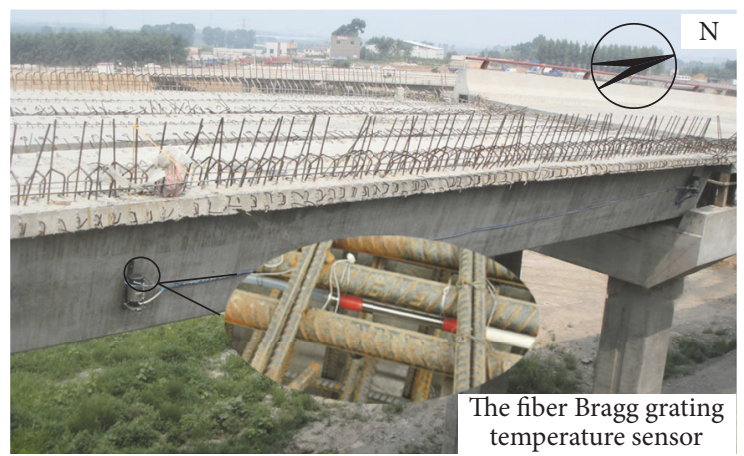

FIGURE 18: View of the bridge and the temperature sensor. 


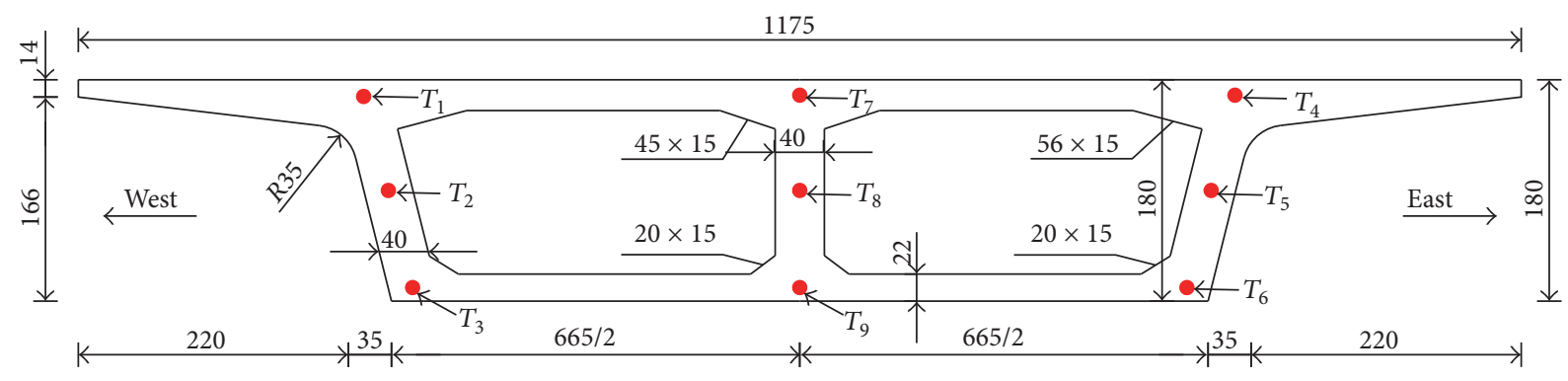

FIGURE 19: Cross-sectional dimension and layout of temperature sensors.

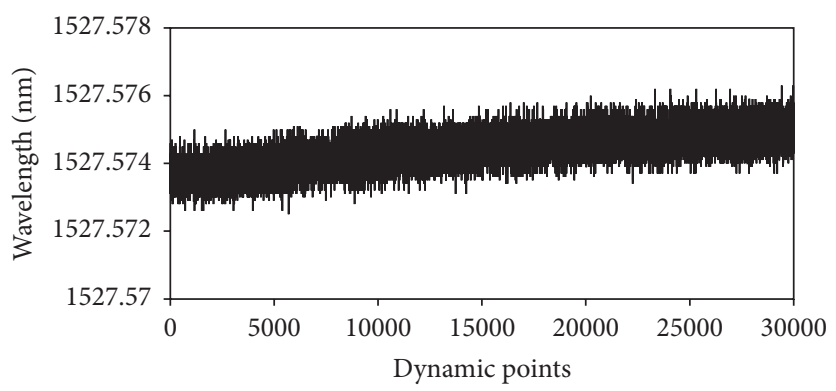

FIGURE 20: Information of 30000 collected wavelengths from 3:00 pm on 9 April 2015.
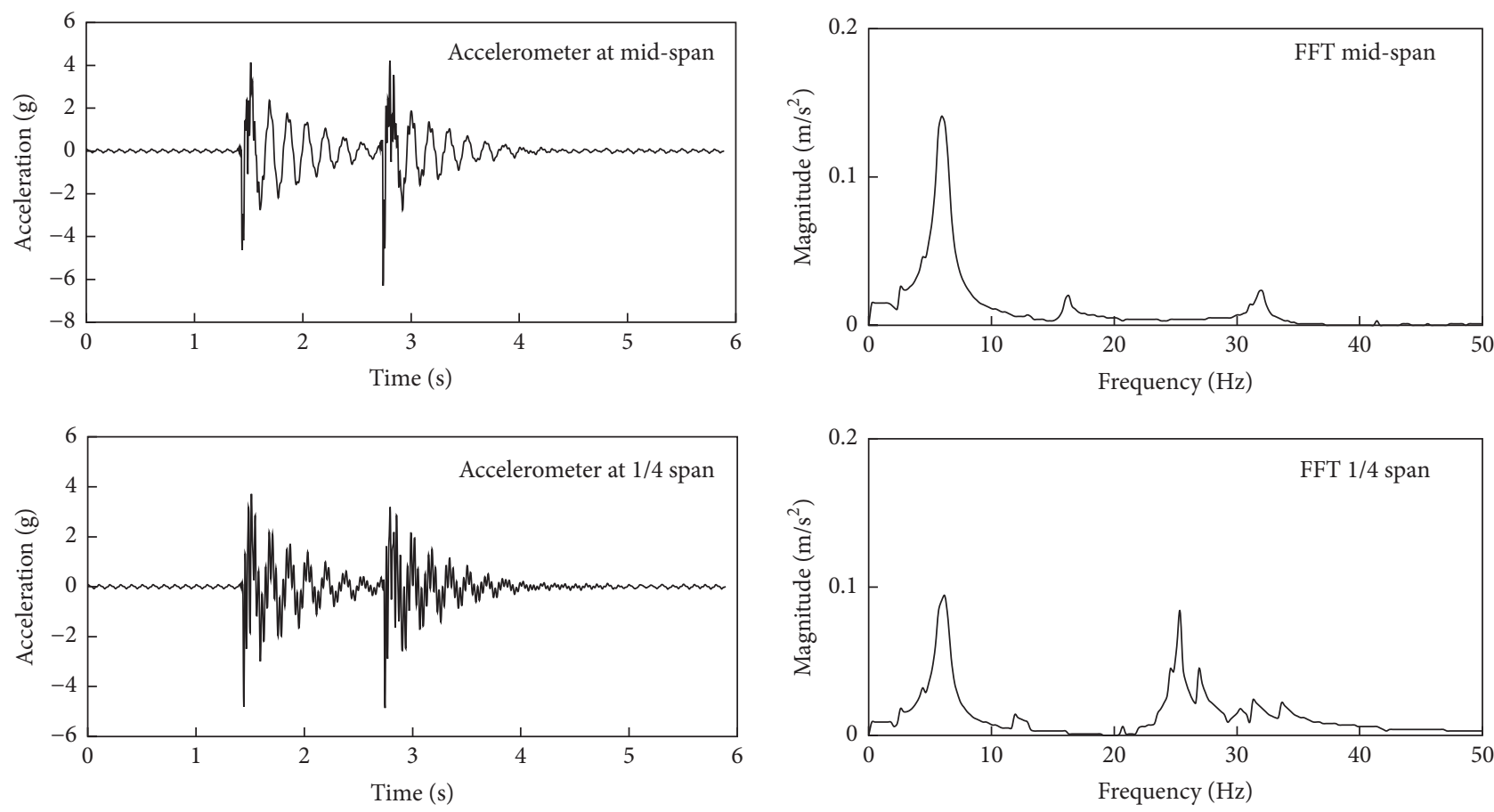

Figure 21: Time and frequency domain information from FFT accelerometers at 15:12 on 9 April 2015.

more consistent with Euler-Bernoulli beam theory relative to the test beam due to the geometrical properties and boundary conditions.

(2) For both the test beam and the actual simply supported box-girder bridge, FVR of the calculation and test frequency results are very close, which reveals that the proposed method possessed favorable accuracy.

(3) The most notable advantage of the proposed method is to accurately calculate natural frequency of the simply supported beam caused by temperature. It can make an 
accurate assessment for bridges by excluding the influence of temperature from the test frequencies.

(4) From the calculation frequency results of the test beam, the variation of elastic modulus induced by temperature is the main reason resulting in the changes of modal characteristics of the test beam, which is consistent with [37]. When the structural deflection increases, the influence of the deflection induced by temperature and the stiffness of bearing on modal characteristics will be more obvious, which is also pointed in [35].

(5) The first three radial modal shapes at different times are basically unchanged. However, the tangential and rotational modal shapes have obvious variations.

This paper investigated the influence of temperature on natural frequency of simply supported beam based on EulerBernoulli beam theory, which may be a main reason leading to some errors between the calculation and test results of the test beam. While the influence of temperature on Timoshenko beam, steel beam, continuous beam, and so forth will be the topics which the authors further deliberate from now on.

\section{Conflicts of Interest}

The authors declare that there are no conflicts of interest regarding the publication of this paper.

\section{Acknowledgments}

This research is supported by National Natural Science Foundation of China in Jilin University (Application code E080510). Help from Professor Yongchun Cheng of Jilin University in providing the data needed is also greatly appreciated.

\section{References}

[1] J.-T. Kim, C.-B. Yun, and J.-H. Yi, "Temperature effects on frequency-based damage detection in plate-girder bridges," KSCE Journal of Civil Engineering, vol. 7, no. 6, pp. 725-733, 2003.

[2] Y. J. Yan, L. Cheng, Z. Y. Wu, and L. H. Yam, "Development in vibration-based structural damage detection technique," Mechanical Systems \& Signal Processing, vol. 21, no. 5, pp. 21982211, 2007.

[3] J.-T. Kim, J.-H. Park, and B.-J. Lee, "Vibration-based damage monitoring in model plate-girder bridges under uncertain temperature conditions," Engineering Structures, vol. 29, no. 7, pp. 1354-1365, 2007.

[4] S. W. Doebling, C. R. Farrar, and M. B. Prime, "A summary review of vibration-based damage identification methods," Shock and Vibration Digest, vol. 30, no. 2, pp. 91-105, 1998.

[5] H. Sohn, C. R. Farrar, F. M. Hemez, and J. J. Czarnecki, "A review of structural health review of structural health monitoring literature 1996-2001," LA-13976-MS, Los Alamos National Laboratory, New Mexico, USA, 2004.

[6] Z.-D. Xu and W. Zhishen, "Simulation of the effect of temperature variation on damage detection in a long-span cable-stayed bridge," Structural Health Monitoring, vol. 6, no. 3, pp. 177-189, 2007.
[7] O. S. Salawu, "Detection of structural damage through changes in frequency: a review," Engineering Structures, vol. 19, no. 9, pp. 718-723, 1997.

[8] H. Sohn, "Effects of environmental and operational variability on structural health monitoring," Philosophical Transactions of the Royal Society A, vol. 365, no. 1851, pp. 539-560, 2007.

[9] C. R. Farrar, S. W. Doebling, P. J. Cornwell, and E. G. Straser, "Variability of modal parameters measured on the alamosa canyon bridge," Tech. Rep., Office of Scientific \& Technical Information Technical Reports, 1996.

[10] M. A. Wahab and G. de Roeck, "Effect of temperature on dynamic system parameters of a highway bridge," Structural Engineering International, vol. 7, no. 4, pp. 266-270, 1997.

[11] P. Cornwell, C. R. Farrar, S. W. Doebling, and H. Sohn, "Environmental variability of modal properties," Experimental Techniques, vol. 23, no. 6, pp. 45-48, 2008.

[12] H. Sohn, M. Dzwonczyk, E. G. Straser, A. S. Kiremidjian, K. Law, and T. Meng, "An experimental study of temperature effect on modal parameters of the Alamosa Canyon Bridge," Earthquake Engineering and Structural Dynamics, vol. 28, no. 7-8, pp. 879-897, 1999.

[13] X. G. Hua, Y. Q. Ni, J. M. Ko, and K. Y. Wong, "Modeling of temperature-frequency correlation using combined principal component analysis and support vector regression technique," Journal of Computing in Civil Engineering, vol. 21, no. 2, pp. 122$135,2007$.

[14] Y. Q. Ni, X. G. Hua, K. Q. Fan, and J. M. Ko, "Correlating modal properties with temperature using long-term monitoring data and support vector machine technique," Engineering Structures, vol. 27, no. 12, pp. 1762-1773, 2005.

[15] H. F. Zhou, Y. Q. Ni, and J. M. Ko, "Constructing input to neural networks for modeling temperature-caused modal variability: mean temperatures, effective temperatures, and principal components of temperatures," Engineering Structures, vol. 32, no. 6, pp. 1747-1759, 2010.

[16] X. He, J. P. Conte, M. Fraser, and E. Ahmed, "Long-term monitoring of a highway bridge," in Proceedings of the $3 \mathrm{rd}$ International Operational Modal Analysis Conference (IOMAC '09), Portonovo, Italy, May 2009.

[17] P. Moser and B. Moaveni, "Environmental effects on the identified natural frequencies of the Dowling Hall Footbridge," Mechanical Systems and Signal Processing, vol. 25, no. 7, pp. 2336-2357, 2011.

[18] B. Peeters and G. De Roeck, "One year monitoring of the Z24-bridge: environmental influences versus damage events," in Proceedings of SPIE-The International Society for Optical Engineering, vol. 2, pp. 1570-1576, May 2000.

[19] B. Peeters, J. Maeck, and G. De Roeck, "Vibration-based damage detection in civil engineering: excitation sources and temperature effects," Smart Materials and Structures, vol. 10, no. 3, pp. 518-527, 2001.

[20] V. Zabel, M. Brehm, and S. Nikulla, "The influence of temperature varying material parameters on the dynamic behavior of short span railway bridges," in Proceedings of the 24th International Conference on Noise and Vibration Engineering (ISMA '10), Leuven, Belgium, September 2010.

[21] Y. L. Xu, B. Chen, C. L. Ng, K. Y. Wong, and W. Y. Chan, "Monitoring temperature effect on a long suspension bridge," Structural Control \& Health Monitoring, vol. 17, no. 6, pp. 632653, 2009.

[22] S. Alampalli, "Influence of in-service environment on modal parameters," in Proceedings of the 16th International Modal 
Analysis Conference, vol. 3243 of SPIE, Santa Barbara, Calif, USA, February 1998.

[23] A. B. Siddique, B. F. Sparling, and L. D. Wegner, "Assessment of vibration-based damage detection for an integral abutment bridge," Canadian Journal of Civil Engineering, vol. 34, no. 3, pp. 438-452, 2007.

[24] B. Peeters and G. De Roeck, "One-year monitoring of the Z24bridge: environmental effects versus damage events," Earthquake Engineering \& Structural Dynamics, vol. 30, no. 2, pp. 149171, 2001.

[25] J. Maeck, B. Peeters, and G. De Roeck, "Damage identification on the Z24 bridge using vibration monitoring," Smart Materials and Structures, vol. 10, no. 3, pp. 512-517, 2001.

[26] P. Cawley, Long Range Inspection of Structures using Low Frequency Ultrasound, Sheffield Academic, Sheffield, UK, 1997.

[27] Y. Q. Ni, H. F. Zhou, K. C. Chan, and J. M. Ko, "Modal flexibility analysis of cable-stayed Ting Kau bridge for damage identification," Computer-Aided Civil and Infrastructure Engineering, vol. 23, no. 3, pp. 223-236, 2008.

[28] C. Jin, J. Li, S. Jang, X. Sun, and R. Christenson, "Structural damage detection for in-service highway bridge under operational and environmental variability," in Proceedings of the Sensors and Smart Structures Technologies for Civil, Mechanical, and Aerospace Systems 2015, vol. 9435 of SPIE, pp. 1629-1633, Denver, Colo, USA, March 2015.

[29] Y. L. Ding and A. Q. Li, “Temperature-induced variations of measured modal frequencies of steel box girder for a long-span suspension bridge," International Journal of Steel Structures, vol. 11, no. 2, pp. 145-155, 2011.

[30] H. F. Zhou, Y. Q. Ni, and J. M. Ko, "Eliminating temperature effect in vibration-based structural damage detection," Journal of Engineering Mechanics, vol. 137, no. 12, pp. 785-796, 2011.

[31] Y. Q. Ni, J. M. Ko, X. G. Hua, and H. F. Zhou, "Variability of measured modal frequencies of a cable-stayed bridge under different wind conditions," Smart Structures and Systems, vol. 3, no. 3, pp. 341-356, 2007.

[32] M. Breccolotti, G. Franceschini, and A. L. Materazzi, "Sensitivity of dynamic methods for damage detection in structural concrete bridges," Shock and Vibration, vol. 11, no. 3-4, pp. 383394, 2004.

[33] Y. Xia, H. Hao, G. Zanardo, and A. Deeks, "Long term vibration monitoring of an RC slab: temperature and humidity effect," Engineering Structures, vol. 28, no. 3, pp. 441-452, 2006.

[34] Y. Fu and J. T. DeWolf, "Monitoring and analysis of a bridge with partially restrained bearings," Journal of Bridge Engineering, vol. 6, no. 1, pp. 23-29, 2001.

[35] A. A. Mosavi, R. Seracino, and S. Rizkalla, "Effect of temperature on daily modal variability of a steel-concrete composite bridge," Journal of Bridge Engineering, vol. 17, no. 6, pp. 979-983, 2012.

[36] Y. Xia, Y.-L. Xu, Z.-L. Wei, H.-P. Zhu, and X.-Q. Zhou, "Variation of structural vibration characteristics versus nonuniform temperature distribution," Engineering Structures, vol. 33, no. 1, pp. 146-153, 2011.

[37] H. B. Liu, X. Q. Wang, and Y. B. Jiao, "Effect of temperature variation on modal frequency of reinforced concrete slab and beam in cold regions," Shock and Vibration, vol. 2016, Article ID 4792786, 17 pages, 2016.

[38] A. Cunha, E. Caetano, F. Magalhães, and C. Moutinho, "Recent perspectives in dynamic testing and monitoring of bridges," Structural Control and Health Monitoring, vol. 20, no. 6, pp. 853877, 2013.
[39] R. Baldwin and M. A. North, "A stress-strain relationship for concrete at high temperatures," Magazine of Concrete Research, vol. 25, no. 85, pp. 208-212, 1973.

[40] Y. Jiao, H. Liu, X. Wang, Y. Zhang, G. Luo, and Y. Gong, "Temperature effect on mechanical properties and damage identification of concrete structure," Advances in Materials Science and Engineering, vol. 2014, Article ID 191360, 10 pages, 2014.

[41] J. Stoer and R. Bulirsch, Introduction to Numerical Analysis, vol. 12 of Texts in Applied Mathematics, Springer-Verlag, New York, NY, USA, 1993.

[42] National Standard of the People's Republic of China, "Code for design of concrete structures," China National Standards GB/T 50010-2002, 2003 (Chinese).

[43] N. E. Huang, Z. Shen, S. R. Long et al., "The empirical mode decomposition and the Hilbert spectrum for nonlinear and non-stationary time series analysis," Proceedings of The Royal Society A: Mathematical, Physical and Engineering Sciences, vol. 454, no. 1971, pp. 903-995, 1998. 


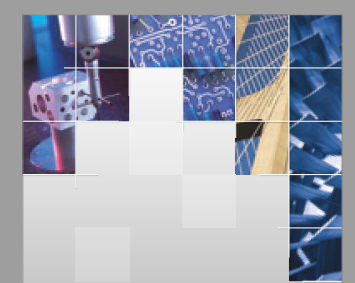

\section{Enfincering}
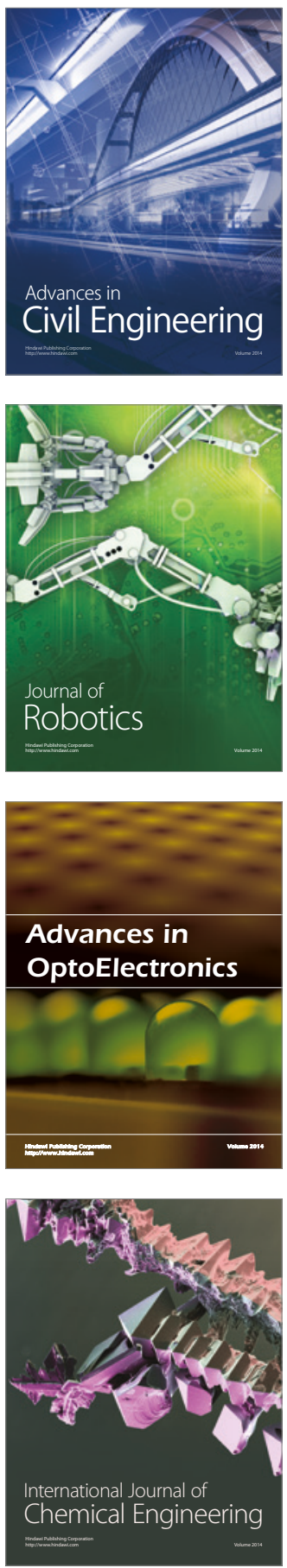

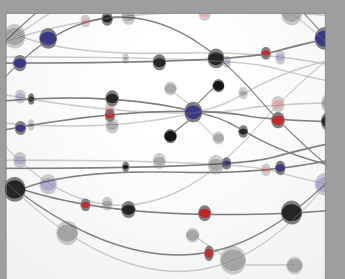

The Scientific World Journal

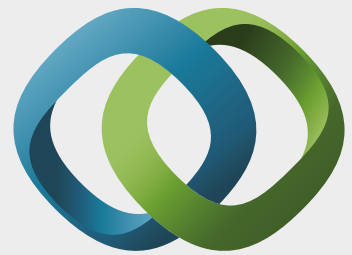

\section{Hindawi}

Submit your manuscripts at

https://www.hindawi.com
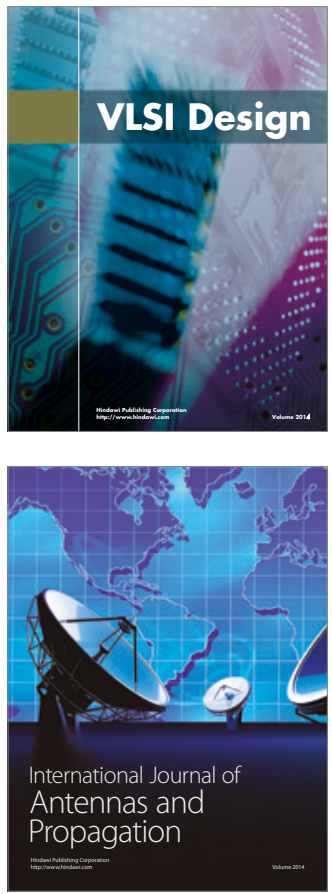

\section{Rotating}

Machinery
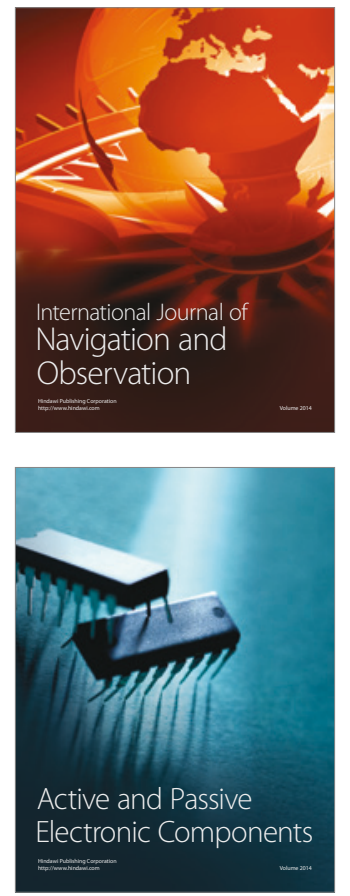
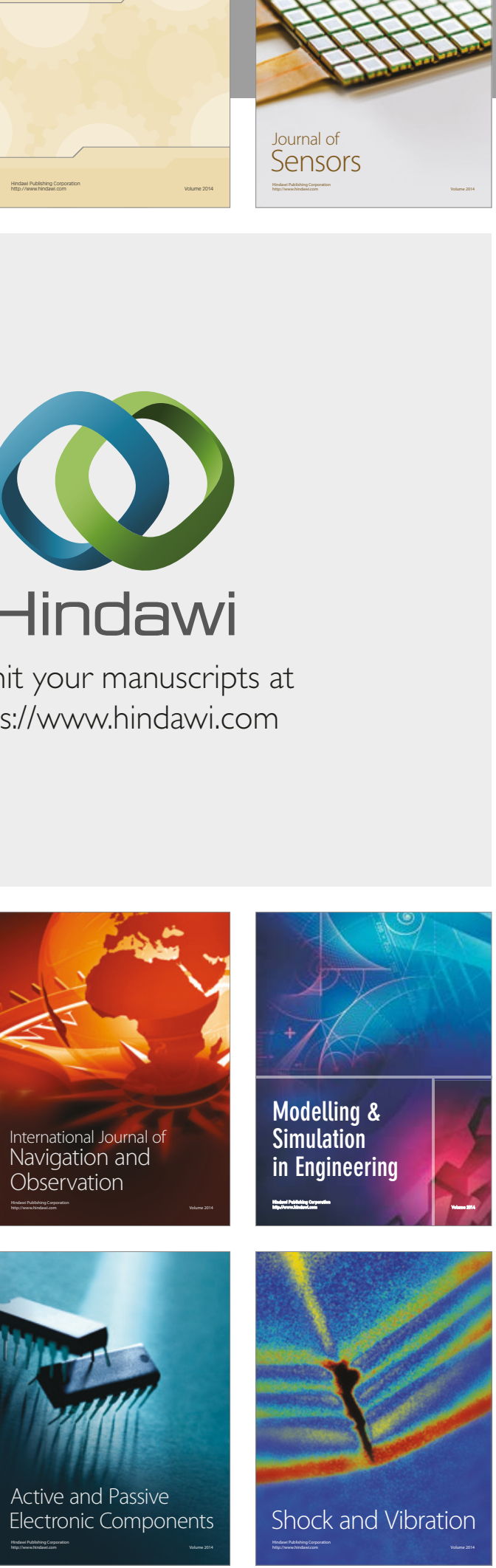
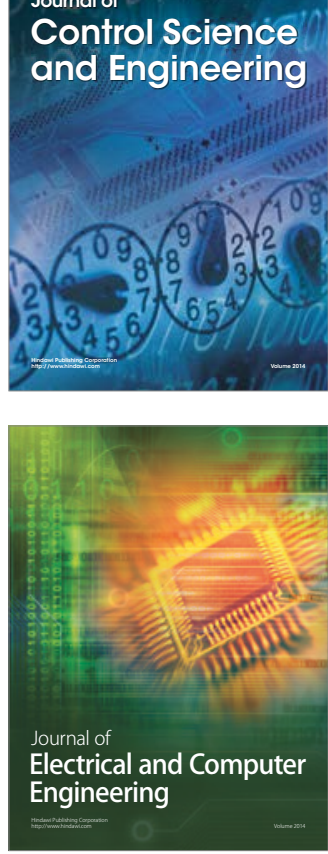

Distributed

Journal of

Control Science

and Engineering
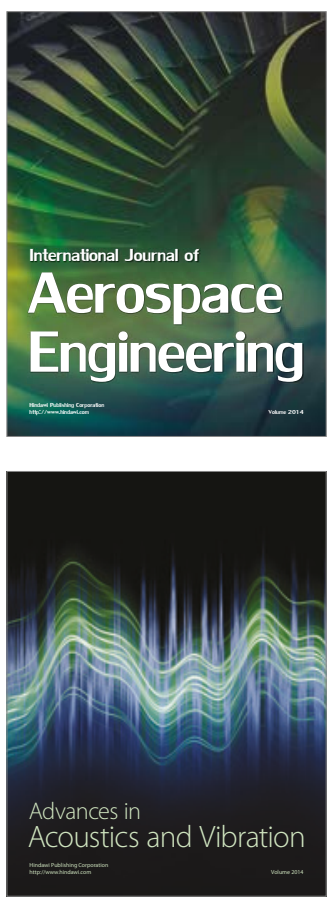

Sensor Networks 